UNIVERSIDADE DE SÃO PAULO
Escola de Engenharia de São Carlos - FMRP/IQSC/EESC

DEISI FERRARI

Capacidade discriminatória e fator de risco de parâmetros eletromiográficos na dor femoropatelar

São Carlos 


\section{DEISI FERRARI}

\section{Capacidade discriminatória e fator de risco de parâmetros eletromiográficos na dor femoropatelar}

\section{VERSÃO CORRIGIDA}

Tese apresentada ao Programa de Pós-graduação Interunidades em Bioengenharia Escola de Engenharia de São Carlos / Faculdade de Medicina de Ribeirão Preto / Instituto de Química de São Carlos da Universidade de São Paulo como parte dos requisitos para a obtenção do título de doutora em Ciências.

Área de Concentração: Bioengenharia

Orientador: Prof. Dr. Neri Alves

Co-orientador: Prof. Dr. Fábio Mícolis de Azevedo

São Carlos 
AUTORIZO A REPRODUÇÃO TOTAL OU PARCIAL DESTE TRABALHO, POR QUALQUER MEIO CONVENCIONAL OU ELETRÔNICO, PARA FINS DE ESTUDO E PESQUISA, DESDE QUE CITADA A FONTE.

\author{
Ferrari, Deisi \\ F375c Capacidade discriminatória e fator de risco de \\ parâmetros eletromiográficos na dor femoropatelar / \\ Deisi Ferrari; orientador Neri Alves; coorientador \\ Fábio Mícolis de Azevedo. São Carlos, 2017. \\ Tese (Doutorado) - Programa de Pós-Graduação \\ Interunidades em Bioengenharia e Área de Concentração \\ em Bioengenharia -- Escola de Engenharia de São \\ Carlos; Faculdade de Medicina de Ribeirão Preto; \\ Instituto de Química de São Carlos, da Universidade de \\ São Paulo, 2017. \\ 1. Dor femoropatelar. 2. Eletromiografia de \\ superfície. 3. Fator de risco. 4. Capacidade \\ discriminatória. I. Título.
}




\section{Universidade de São Paulo}

Programa de Pós-Graduação Interunidades em Bioengenharia

Escola de Engenharia de São Carlos

Faculdade de Medicina de Ribeirão Preto

Instituto de Química de São Carlos

\section{DEISI FERRARI}

Título: "Capacidade discriminatória e fator de risco de parâmetros eletromiográficos na dor femoropatelar"

TESE APRESENTADA PROGRAMA DE pós GRADUAÇÃO INTERUNIDADES EM BIOENGENHARIA EESC/FMRP/IQSC DA UNIVERSIDADE DE SÃO PAULO PARA OBTENÇÃO DO TÍTULO DE DOUTORA EM CIÊNCIAS NA ÁREA DE BIOENGENHARIA.

Data da defesa: 01/09/2017

\begin{tabular}{|l|l|}
\hline Prof. Dr. Fábio Mícolis de Azev o Coorientador & FCT/UNESP \\
\hline Assinatura: & Resultado: Amn \\
\hline \\
\hline Prof. Dr. Fernando Henrique Magalhães & EACH/USP \\
\hline Assinatura: & Resultado: Aprovadu \\
\hline
\end{tabular}

\begin{tabular}{|l|l|}
\hline Prof. Dr. Rúben de Faria Negrão Filho & RCT/UNESP \\
\hline Assinatura:
\end{tabular}

Prof. Dr. Nivaldo Antonjo Parizotto 1 UFSCar

Homologado em: 


\section{AGRADECIMENTOS}

Muitos foram os que contribuíram para a realização deste trabalho, mas sem dúvida, Deus é o nosso mestre e nada aconteceria sem sua presença. Ter fé é um privilégio de poucos, e neste período de doutorado isto ficou muito claro. Acreditar que existe um Ser Superior que zela

por ti é confortante e me deu forças para enfrentar as dificuldades. À Ele, meu Muito

Obrigada!

Agradeço aos meus pais, Airton Francisco Ferrari e Marlice Lourdes Kuhn Ferrari, pelo carinho, dedicação e palavras de força e motivação incondicionais. Quem ama cuida e mesmo à distância, posso senti-los me abençoando e torcendo por mim! Tenho meus pais como exemplo de vida, e se eu puder ser para meus filhos o que eles são para mim, estarei realizada plenamente.

Ao meu amado irmão, Willian Ferrari, agradeço por sempre me fazer lembrar que acima de tudo sou humana e que nesta condição, não posso ignorar as coisas importantes que fazem a vida ter sentido. Obrigada maninho, pelas palavras sábias e pelas "baitas” risadas gostosas.

Neste período de doutorado fui namorada, noiva e muito em breve esposa! Agradeço imensamente ao meu noivo, Sandro Satio Suzuki, pela paciência, compreensão, carinho, força e apoio neste período de doutorado. Você fez parte dos momentos mais importantes e difíceis da minha vida, mesmo que muitas vezes a distância, nunca deixou de estar ao meu lado me aconselhando e me confortando. Amo você!

Aos queridos amigos (as), Bruna Spolador, Lara Peixoto, Fernanda Messali, Franciele Gazola,

Cassiane Merigo, Juliana Pradela, Gabriel Faustino, Alessandro Hakme e Crisiane pelas alegrias, companheirismo e ajuda sempre que precisei. Agradeço em especial a Priscila Kalil Morelhão, minha irmã de coração. Sem dúvida, minha vida de doutoranda não seria a mesma sem você e eu só tenho a agradecer pela sua amizade, conselhos, risadas e companheirismo. Sua bondade, honestidade, humildade, dedicação, empenho, esforço e fé tornam você uma pessoa muito especial que eu admiro muito e tomo como exemplo. Não posso deixar de agradecer também, minha doce amiga Cynthia Gobbi! Apesar de pouco tempo de amizade (nos conhecemos a pouco tempo), você foi muito importante para mim, me trouxe esperança e 
força, nos momentos de angústia. Obrigada queridas amigas (os)! Levarei vocês no meu coração!

Agradeço aos amigos de Sydney, Thiago Jambo, Anita, Juliana, Marina, Maurício, Poliana, Shiek, Evangelos que foram essenciais no meu processo de adaptação, me orientando e ajudando em tudo que precisei. São pessoas guerreiras que conheci e não mais esquecerei! Saudades!

Ao meu orientador, Neri Alves, pelo incentivo, apoio e ajuda no desenvolvimento do meu projeto, no doutorado sanduíche e a bolsa de estudos. Além de contribuir para meu crescimento profissional e pessoal. Muito obrigada professor, sem você este doutorado não seria possível. De maneira muito especial, agradeço imensamente ao meu coorientador Fábio Mícolis de Azevedo. Te agradeço por todas as conquistas que tive desde o mestrado, pois você esteve presente o tempo todo, me orientando e ajudando no que fosse preciso. Te admiro muito pelas suas habilidades intelectuais, sua sabedoria e competência em orientar alunos, criar e gerenciar um grupo de pesquisa tão competente. Professor Fábio e Neri, posso dizer que o caminho é muito mais fácil quando temos mestres do nosso lado. Muito obrigada!

Aos colegas e amigos de trabalho, em especial o Ronaldo, a Marcella, a Amanda e o Danilo, muito obrigada! Vocês foram muito importantes para meu crescimento acadêmico e pessoal. Compartilhamos muitos momentos alegres e de conquistas, os quais não serão esquecidos. Aprendi muito com as diferentes habilidades e características individuais, e acima de tudo aprendi com vocês, que com dedicação e empenho o sucesso profissional é possível.

Aos professores, Rúben de Faria Negrão Filho, Evangelos Pappas, Fernando H. Magalhães, Orivaldo, Eugênia que, cada um da sua maneira, contribuíram para a minha formação. À todos os colegas, professores e funcionários do Programa de Pós-Graduação Interunidades Bioengenharia, que cada um na sua área contribuíram para minha formação.

À todos que participaram na execução desta pesquisa, especialmente ao grupo de pesquisa e a todas as voluntárias, pois sem eles este trabalho não seria possível.

Enfim, Agradeço a todas as pessoas que contribuíram direta ou indiretamente para o meu crescimento humano, social e intelectual. 


\section{RESUMO}

\section{FERRARI, D. Capacidade discriminatória e fator de risco de parâmetros}

eletromiográficos na dor femoropatelar. 2017. Tese (Doutorado) - Programa de PósGraduação Interunidades em Bioengenharia - Escola de Engenharia de São Carlos - EESC/ Faculdade de Medicina de Ribeirão Preto - FMRP/ Instituto de Química de São Carlos IQSC, Universidade de São Paulo, São Carlos, 2017.

Apesar da dor femoropatelar (DFP) apresentar alta incidência e prognóstico desfavorável, sua etiologia permanece obscura e seu diagnóstico clínico e funcional indefinido. Acredita-se que uma das causas da DFP seja a alteração na ativação dos músculos vasto medial (VM) e vasto lateral (VL), porém são escassos os estudos que investigam parâmetros eletromiográficos no domínio da frequência destes músculos. Portanto, o objetivo é analisar parâmetros da frequência, obtidos por dois métodos de processamento, para identificação de padrões eletromiográficos em mulheres com DFP que apresentem elevada capacidade discriminatória, correlação com a dor e que possam ser considerados como fator de risco. O sinal eletromiográfico dos músculos VM e VL de 80 mulheres (40 mulheres assintomáticas e 40 mulheres com DFP) foi coletado durante a subida de escada. Considerou-se para análise o sinal eletromiográfico correspondente à componente vertical da força de reação do solo $(\mathrm{Fz}) \mathrm{e}$ à loading rate (LR) da Fz. Os parâmetros eletromiográficos foram comparados entre os grupos e testados quanto à (ao) reprodutibilidade, capacidade discriminatória, associação com a dor e fator de risco. Os resultados evidenciaram que os parâmetros eletromiográficos correspondentes à Fz e a LR da Fz são reprodutíveis e estão alterados em pacientes com DFP. Entretanto, os parâmetros do sinal eletromiográfico correspondente à Fz apresentaram valores altos de correlação com a dor e capacidade discriminatória quando comparados ao segundo processamento. Além disso, a alteração eletromiográfica, representada pela banda de frequência entre 45 e $96 \mathrm{~Hz}$ do VL, mostrou ser um possível fator de risco para DFP. Os achados deste estudo mostram uma nova abordagem na interpretação e aplicabilidade das alterações eletromiográficas dos músculos VM e VL, evidenciando que alterações de controle neuromuscular devem ser consideradas no processo de avaliação, tratamento e prevenção da DFP.

Palavras-chave: Dor femoropatelar. Eletromiografia de superfície. Fator de risco. Capacidade discriminatória. 


\begin{abstract}
FERRARI, D. Discriminatory capacity and risk fator of electromyography parameters in the patellofemoral pain. 2017. Thesis (PhD) - Programa de Pós-Graduação Interunidades em Bioengenharia - Escola de Engenharia de São Carlos - EESC/ Faculdade de Medicina de Ribeirão Preto - FMRP/ Instituto de Química de São Carlos - IQSC, Universidade de São Paulo, São Carlos, 2017.
\end{abstract}

Despite the patellofemoral pain (PFP) has high incidence and unfavorable prognosis, its etiology remains unclear and clinical diagnosis indefinite. It is believed that one of the causes of PFP is the muscle activation altered of the vastus medialis (VM) and vastus lateralis (VL), however there are few studies that investigate electromyographic parameters in the frequency domain in these muscles. Therefore, the purpose is to analyze parameters of the frequency domain, using two different processing methods, to identify electromyographic patterns in women with PFP that have high discriminatory capacity, correlation with pain and that could be a risk factor. The electromyography signal of the VM and VL muscles of the 80 women (40 pain-free women and 40 women with PFP) was collected during stair ascend. Electromyography signal related to vertical ground reaction force $(\mathrm{Fz})$ and loading rate (LR) of Fz was considered to analysis. Electromyography signal was compared between groups and tested about the reliability, discriminatory capacity, correlation with pain and risk factor. Results evidenced that electromyography signal related to $\mathrm{Fz}$ and $\mathrm{LR}$ are reliable and altered in women with PFP. However, electromyography signal related to Fz has higher values of correlation with pain and discriminatory capacity than electromyography signal related to LR. Furthermore, the altered electromyography signal, represented by the frequency between 45 and $96 \mathrm{~Hz}$ of the VL muscles, may be consider a risk factor for PFP. Findings of this study show a new approach for understanding and applicability of the altered electromyography signal of the VL and VM muscles, evidencing that changes in the neuromuscular control should be considered in the assessment, management and prevention of the PFP.

Keywords: Patellofemoral pain. Surface Electromyography. Risk factor. Discriminatory capacity. 


\section{LISTA DE FIGURAS}

Figura 1 - Fluxograma representando o delineamento experimental do estudo..................................... 30

Figura 2 - Escada utilizada para a realização do gesto de estudo........................................................... 34

Figura 3 - Eletroestimulador utilizado para localização do ponto motor ............................................... 35

Figura 4 - Pontos de referência para o posicionamento da transparência .............................................. 36

Figura 5 - Pontos de referência para o posicionamento da transparência ............................................... 36

Figura 6 - Representação do sinal eletromiográfico referente à Fz........................................................ 39

Figura 7 - Representação do sinal eletromiográfico referente à LR ...................................................... 39

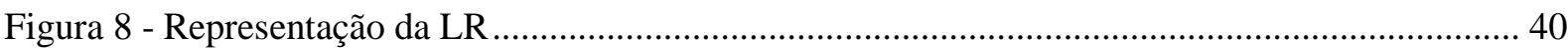




\section{LISTA DE TABELAS}

Tabela 1 - Valores descritivos e de reprodutibilidade dos parâmetros eletromiográficos correspondentes à Fz do grupo DFP e controle.

Tabela 2 - Valores descritivos e de reprodutibilidade dos parâmetros eletromiográficos correspondentes à LR do grupo DFP e controle.

Tabela 3 - Comparação entre grupo controle e DFP das variáveis eletromiográficas correspondentes à Fz. 46

Tabela 4 - Comparação entre o grupo controle e DFP das variáveis eletromiográficas correspondentes

à LR 47

Tabela 5 - Associação entre a variável dor e as variáveis eletromiográficas correspondentes à Fz...... 48

Tabela 6 - Associação entre a variável dor e as variáveis eletromiográficas correspondentes à LR .... 48

Tabela 7 - Valores de acurácia discriminatória dos parâmetros eletromiográficos. 49 


\section{LISTA DE ABREVIATURAS E SIGLAS}

AUC - Area under the curva / Área sob a curva

Banda I - Banda de frequência entre 15 a $45 \mathrm{~Hz}$

Banda II - Banda de frequência entre 45 a $96 \mathrm{~Hz}$

Banda III - Banda de frequência entre 95 a $400 \mathrm{~Hz}$

Banda IV - Banda de frequência entre 10 a $30 \mathrm{~Hz}$

CVM - Contração voluntária máxima

DFP - Dor femoropatelar

DP - Desvio padrão

EPM - Erro padrão da medida

EVA - Escala visual analógica

Fm - Frequência média

Fmed - Frequência mediana

FRS - Força de reação do solo

$\mathrm{Fz}$ - Componente vertical da força de reação do solo

ICC - Coeficiente de correlação intraclasse

LABCOM - Laboratório de biomecânica e controle motor

LR - Loading rate

M - Média aritmética

OR - Odds ratio / razão de chance

PSD - Power spectral density / densidade espectral de potência

$\mathrm{RF}$ - Músculo reto femoral

ROC - Receiver operating characteristic curve

UM - Unidades motoras

VL - Músculo vasto lateral

VM - Músculo vasto medial

TDF - Transformada discreta de Fourier 


\section{SUMÁRIO}

1. INTRODUÇÃO ……......................................................................................................................................13

2. OBJETIVOS

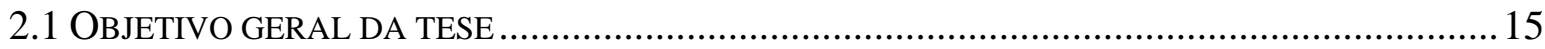

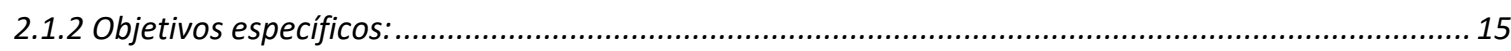

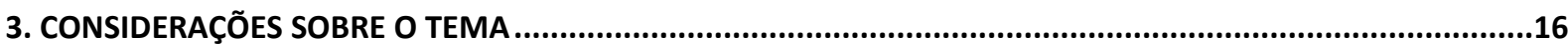

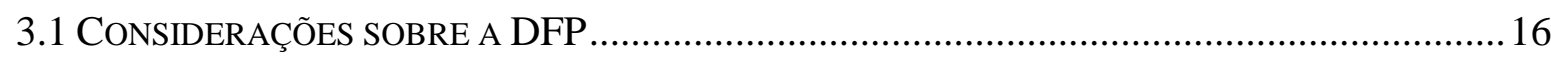

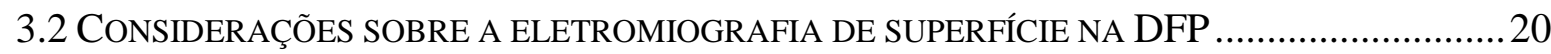

3.3 CONSIDERAÇÕES SOBRE CAPACIDADE DISCRIMINATÓRIA E FATOR DE RISCO ....................25

4. MATERIAL E MÉTODOS ….................................................................................................................

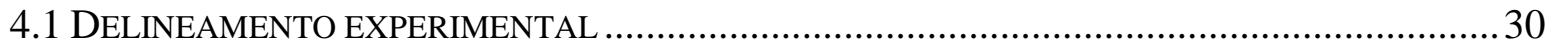

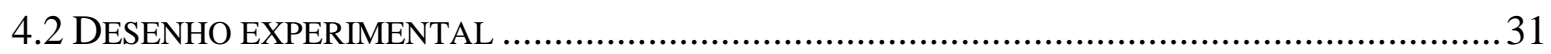

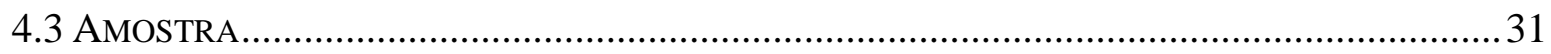

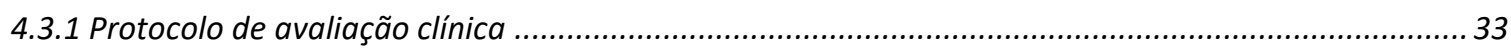

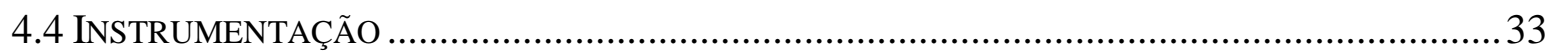

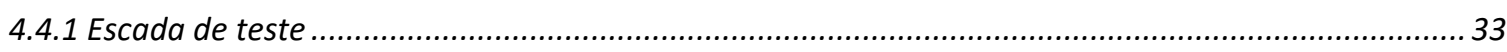

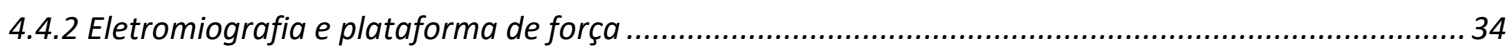

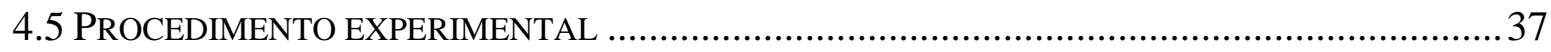

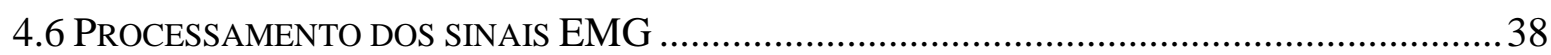

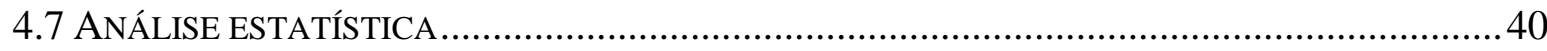

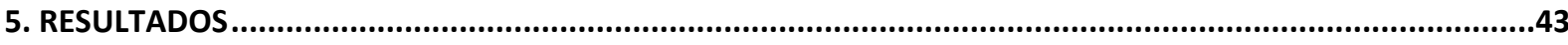

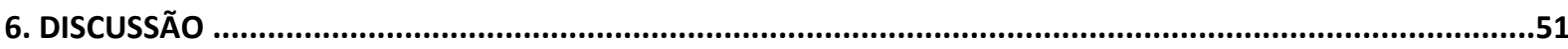

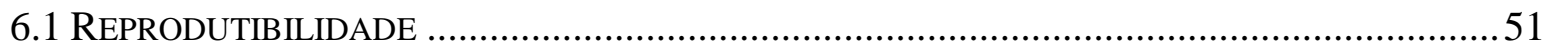

6.2. ANÁLISE QUALITATIVA DO SINAL ELETROMIOGRÁFICO: GRUPO CONTROLE VS GRUPO DFP

.52

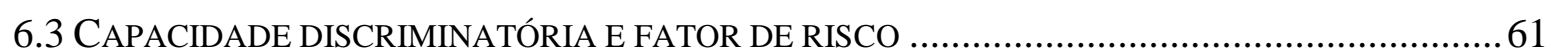

7. CONCLUSÃO

REFERÊNCIAS BIBLIOGRÁFICAS .......................................................................................................66

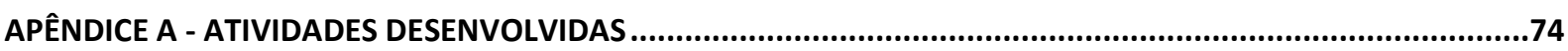

ANEXO A - APROVAÇÃO DO PROJETO PELO COMITÊ DE ÉTICA EM PESQUISA DA FCT/UNESP .........................78

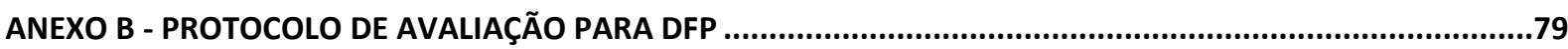




\section{INTRODUÇÃ̃}

A DFP é uma desordem musculoesquelética que apresenta alta incidência e, dependendo do estágio em que se encontra, ela pode comprometer o desempenho de atividades funcionais ou a prática esportiva. Apesar de ser a queixa principal nas clínicas ortopédicas e comprometer 1 em cada 4 indivíduos fisicamente ativos, a DFP permanece com sua etiologia indefinida. Autores defendem que a causa seja multifatorial, compreendendo alterações proximais, locais e distais ao joelho. Dentre os fatores locais, destacam-se as alterações eletromiográficas dos músculos estabilizadores da patela, o músculo VM e o VL. Análises no domínio do tempo do sinal eletromiográfico foram por muito tempo estudas na DFP, entretanto, os resultados são bastante controversos e os autores não chegam a um consenso sobre o tema. Paralelamente, alterações no domínio da frequência do sinal eletromiográfico foram encontrados em indivíduos com DFP, apresentando unanimidade nos achados. Apesar de a literatura ser consistente em relação as alterações eletromiográficas no domínio da frequência em mulheres com DFP, pouco se sabe sobre as implicações clinicas destes resultados. Neste contexto, o presente estudo, se propõe a investigar estas alterações eletromiográficas qualitativamente, possibilitando a compreensão e, possíveis aplicações clínicas destes achados. Além disso, a análise da capacidade discriminatória foi realizada para entender a proporção de indivíduos que realmente apresentam esta alteração, bem como o quanto estas alterações se correlacionam com a dor reportada. Considerando a unanimidade dos achados em relação as alterações eletromiográficas no domínio da frequência em indivíduos com DFP, é de grande valia entender se existe algum padrão eletromiográfico associada a DFP que possa ser considerada como fator de risco.

Para tornar as análises mais específicas e possivelmente melhorar os resultados de capacidade discriminatória dos parâmetros eletromiográficos, foi proposto dois tipos de 
processamento do sinal. Analisou-se o sinal eletromiográfico correspondente à Fz da força de reação do solo e à LR da Fz. De acordo com a literatura, indivíduos com DFP apresentam altos valores de LR o qual está associado com a presença da dor. Portanto, testou-se a hipótese de que os parâmetros eletromiográficos extraídos no mesmo instante em que a LR ocorre, poderiam apresentar resultados superiores de reprodutibilidade, capacidade discriminatória e maior correlação com a dor que os parâmetros eletromiográficos correspondentes à Fz.

Baseado em estudos prévios reportados na literatura e, especialmente, desenvolvidos no grupo de estudo que participo (Laboratório de Biomecânica e Controle Motor LABCOM), acredita-se que as alterações eletromiográficas estão de fato presentes em mulheres com DFP. Entretanto, a utilização de eletromiógrafos na prática clínica, parece ser uma realidade distante, tanto pelo custo quanto pela operacionalização. Neste contexto, durante o período de doutorado, realizei uma pesquisa no exterior para investigar a reprodutibilidade e capacidade discriminatória de um dispositivo de eletromiografia vestível. Este dispositivo, consiste em um "shorts" com sensores eletromiográficos posicionados na região dos músculos quadríceps e isquiotibiais. O sinal eletromiográfico foi coletado durante algumas tarefas específicas (subida e descida de escada, agachamento bi e unipodal) e os dados enviados por "bluetooth" para o computador ou celular. Os dados foram analisados e o artigo está em análise pelos autores. Maiores informações sobre este projeto e a descrição das atividades acadêmicas desenvolvidas durante o período de doutorado poderão ser encontradas no Apêndice A deste documento. 


\section{OBJETIVOS}

\subsection{OBJETIVO GERAL DA TESE}

Analisar os parâmetros do domínio da frequência do sinal eletromiográfico quanto à sua capacidade discriminatória e identificar padrões eletromiográficos que podem ser considerados fatores de risco para DFP.

\subsubsection{Objetivos específicos:}

a) investigar a reprodutibilidade e precisão dos parâmetros eletromiográficos correspondentes à Fz e LR;

b) investigar se os parâmetros eletromiográficos, correspondentes à Fz e LR, apresentamse alterados nas mulheres com DFP;

c) investigar se os parâmetros eletromiográficos, correspondentes à Fz e LR, apresentam correlação com a dor referida;

d) testar a capacidade discriminatória dos parâmetros eletromiográficos correspondentes à Fz e LR;

e) investigar se as alterações eletromiográficas que apresentaram melhor correlação com a dor referida podem ser consideradas como um fator de risco para a DFP. 


\section{CONSIDERAÇÕES SOBRE O TEMA}

\subsection{CONSIDERAÇÕES SOBRE A DFP}

O joelho é considerado uma das articulações mais lesionadas na prática esportiva, assim como nas atividades de vida diária (1). Dentre a grande variedade de patologias que acometem essa articulação, destaca-se a DFP, que compreende até $25 \%$ dos problemas de joelho na população em geral (2).

Define-se a DFP como uma dor na região anterior do joelho na ausência de outra condição patológica que exacerba-se durante a realização de atividades esportivas, agachamentos, subida e descida de escada e permanecer sentado por tempo prolongado $(2,3)$. Na prática clínica, a DFP compreende de $25 \%$ a $40 \%$ de todos os problemas de joelho tratados nas clínicas de medicina do esporte $(2,3)$ e afeta 1 em cada 4 indivíduos fisicamente ativos (4). Stathopulu et al. (2003) analisou pacientes com DFP em um período de 4 a 18 anos depois da primeira consulta e revelou que $91 \%$ dos indivíduos ainda se queixavam de dor no joelho e 36\% apresentavam restrições funcionais (5). Além disso, a literatura aponta para a associação da DFP com o desenvolvimento de osteoartrite, assim a DFP seria uma condição precursora da osteoartrite patelofemoral $(6,7)$.

Frequentemente a DFP é diagnosticada em pessoas entre 16 e 25 anos de idade (4), sendo 2.23 vezes mais frequente em mulheres do que em homens (8). Outro estudo monitorou 446 estudantes selecionados aleatoriamente, em um período de 7 anos, e demonstrou que 18,1\% dos indivíduos eram homens e 33,2\% eram mulheres diagnosticados com DFP. Também observou-se que $30 \%$ deles apresentaram dor retropatelar nos últimos anos e $18 \%$ pararam de praticar atividades físicas em decorrência do desconforto no joelho (9). 
Apesar da alta prevalência e incidência, os fatores etiológicos da DFP não estão claramente definidos. Acredita-se que os fatores causais sejam multifatoriais, destacando-se alterações proximais, distais e locais à articulação do joelho (10).

Os fatores proximais incluem principalmente alterações do quadril, destacando-se disfunções na ativação do glúteo médio e máximo e diminuição da força de contração dos abdutores e rotadores externos de quadril (11-13), além de angulação excessiva de adução de quadril e rotação interna do fêmur (14-17). Em atividades que requerem descarga de peso unipodal, como subida de escada, essa excessiva angulação provoca demasiado valgo dinâmico do joelho e gera picos de contato pressóricos, podendo aumentar em $45 \%$ a pressão na articulação patelofemoral (18). Para exemplificar como essas variáveis se comportam, Noehren et al. (2013) (19) encontraram em atividades unipodais, diferença significativa ( $\mathrm{p}=$ $0,007)$ na adução de quadril quando comparando a indivíduos com $\left(12,1 \pm 2,8^{\circ}\right)$ e sem DFP $\left(8,1 \pm 4,8^{\circ}\right)$; e McKenzie et al. (20) encontraram excessiva rotação interna de fêmur nos indivíduos com DFP durante subida e descida de escadas. Tais alterações podem provocar lateralização da patela, aumentando a pressão de contato com o côndilo femoral, e consequentemente desencadear os sintomas da DFP.

O principal fator distal pesquisado é a hiperpronação subtalar (21-23). Acredita-se que a excessiva amplitude de movimento de pronação subtalar durante a marcha resulta em excessiva rotação interna da tíbia, atrasando ou reduzindo a amplitude de rotação externa da tíbia em relação ao fêmur. Com a redução da rotação externa e aumento da rotação interna da tíbia, durante o movimento de extensão do joelho na fase de apoio, o fêmur realiza um movimento compensatório de excessiva rotação interna aumentando a área de contato da articulação patelofemoral. Consequentemente, estas alterações aumentam a compressão lateral na articulação e propicia o desenvolvimento da doença (24). Neste contexto, Barton et al (2011) investigaram o movimento de pronação subtalar, por meio da análise cinemática, e 
observou que indivíduos com DFP apresentam hiperpronação subtalar (21). Além disso, de acordo com uma revisão sistemática, a hiperpronação subtalar foi apontada como uma das principais características da marcha de indivíduos com DFP (25) e é considerada um fator de risco para o desenvolvimento da DFP (26).

Em relação aos fatores locais, existe uma hipótese que destaca a existência de um desalinhamento patelar decorrente de uma alteração na atividade dos estabilizadores mediais e laterais da articulação patelofemoral, os músculos VM e VL (27). Sugere-se que disfunções no controle neuromotor dos músculos VM e VL podem ocorrer e gerar forças de diferentes amplitudes em um mesmo instante ou atraso em suas ativações, causando um deslocamento lateral da patela, irritando os tecidos moles da articulação (28). Hipoteticamente, considera-se que a ativação do VM inicia anteriormente à ativação do VL, no sentido de manter o equilíbrio do deslizamento da patela, o que pode não ocorrer nos indivíduos com DFP (29). Para verificar se há um desequilíbrio entre o VM e o VL, e se essa disfunção do quadríceps é um dos fatores etiológicos da DFP, muitos autores têm estudado a ativação destas porções por meio da eletromiografia de superfície (EMG) (30-33), no entanto, os resultados são conflitantes $(34,35)$. Cavazzuti et al., investigaram o atraso na ativação do VM e VL em atividades funcionais, tais como subida de escada, e não encontrou resultados que suportam a associação do atraso de ativação com a presença da DFP (29), igualmente observado por outros autores $(32,33)$. Entretanto, diferenças no tempo de início de ativação do VM e VL em indivíduos com DFP foram reportados em outros estudos (28,36,37). Enquanto inconsistências relacionadas ao tempo de início da ativação do VM e VL não são resolvidas, alterações do controle neuromuscular em indivíduos com DFP, foram evidenciadas pela análise de parâmetros do domínio da frequência do sinal eletromiográfico dos músculos VL e VM $(33,38)$. Sugere-se que as mudanças encontradas nas propriedades espectrais sejam reflexos de alterações na ativação ou inibição muscular (39). Embora alterações 
eletromiográficas baseadas nas análises do domínio da frequência evidenciem padrões anormais em indivíduos com dor, não está definido, na literatura, as possíveis causas e consequências de tal condição.

Além das alterações eletromiográficas, observam-se alterações cinemáticas locais nos indivíduos com DFP, destacando entre elas, a diminuição do ângulo de flexão do joelho $(20,40)$. Sabe-se que durante as atividades de descarga de peso unipodal, o aumento na flexão do joelho aumenta a força de reação da articulação patelofemoral (41). Assim, os indivíduos com DFP reduzem a quantidade de flexão do joelho na tentativa de reduzir a força de reação da articulação patelofemoral e, consequentemente, aliviar a dor nessa região $(41,42)$. Cabe salientar, ainda, que o pico de flexão do joelho é considerado um fator de risco para DFP e é capaz de predizer $71 \%$ da dor (26)

Sabe-se que a diminuição do ângulo de flexão do joelho e as alterações na ativação dos músculos do quadríceps repercutem no aumento do estresse de estruturas osteomusculares, as quais podem estar relacionadas aos altos valores de LR (taxa da velocidade em que uma força é aplicada no corpo) (43-45). Parte desta teoria foi testada por De Oliveira, et al que investigou o comportamento do ângulo de flexão do joelho e a LR em mulheres com e sem DFP. Os resultados evidenciaram que mulheres com DFP apresentam ângulo de flexão de joelho reduzido e altas taxas de LR (46), ratificando a hipótese de que mulheres com DFP reduzem a flexão de joelho para minimizar a dor, influenciando no aumento da LR. Entretanto, a relação entre as alterações na ativação dos músculos VM/VL e a LR em mulheres com DFP não está clara na literatura. Portanto, torna-se relevante investigar se alterações eletromiográficas do VM/VL são mais evidentes no momento em que a LR ocorre e assim, possibilitar uma possível explicação para a dor reportada pelos indivíduos com DFP. 


\subsection{CONSIDERAÇÕES SOBRE A ELETROMIOGRAFIA DE SUPERFÍCIE NA DFP}

A eletromiografia de superfície é uma das principais técnicas utilizadas na área da biomecânica. Ela é um método que permite o registro e monitoração dos potenciais de ação das membranas de fibras musculares em contração, possibilitando desta forma o estudo da função muscular por meio da análise dos sinais elétricos. A utilização da eletromiografia tem como propósitos fundamentais: servir como indicador de estresse muscular, padrões de movimentos e identificar parâmetros de controle do sistema nervoso (47); e portanto, tem proporcionado a investigação de padrões normais e patológicos, processo de fadiga (48), análise de controle motor (30) e, ainda, sua utilização como ferramenta de diagnóstico $(38,49)$.

O sinal eletromiográfico pode ser submetido, basicamente, a dois tipos de análises: no domínio da frequência e do tempo. Os parâmetros comumente analisados no domínio da frequência são a frequência mediana (Fmed), a frequência média (Fm) e a potência em bandas específicas. A Fmed representa o centro geométrico da PSD (power spectral density), ou seja, a frequência na qual a densidade do espectro encontra-se dividida em duas regiões de áreas iguais. A Fm representa a média ponderada da PSD (50). A decomposição do sinal em bandas de frequência permite que sejam empregados métodos de processamento para extração de parâmetros que refletem alterações mais específicas em determinadas faixas do espectro. Neste caso, não é observado o reflexo global das alterações do espectro de frequência, mas o comportamento específico de bandas selecionadas durante a ativação do músculo. De acordo com o encontrado na literatura não existe um consenso sobre a forma de divisão do espectro de potência, porém estudos que utilizam esse tipo de análise fazem a divisão do espectro em duas bandas, as quais geralmente recebem o nome de baixa e alta frequência (51), ou dividem o espectro em três bandas denominadas de baixa, média e alta frequência $(33,38,52,53)$. 
Possíveis inferências foram testadas por diversos estudos em relação ao espectro de frequência e sua aplicabilidade. Dentre as hipóteses testadas, a relação entre o comportamento do espectro de potência e os tipos de fibra muscular e/ou padrões de recrutamento das unidades motoras (UM) foi amplamente investigada (51,53-58). Gerdle et al., (1991) (56) investigou se a Fm do sinal eletromiográfico dos músculos extensores de joelho era dependente da força e/ou tipo de fibra. Neste estudo, 10 mulheres desenvolveram uma força gradual durante a extensão do joelho no isocinético (contração voluntária máxima - CVM). Durante este procedimento, o sinal eletromiográfico foi coletado simultaneamente e após a coleta de dados, foi realizada a biópsia dos músculos VL para determinar a proporção e a área dos diferentes tipos de fibra. Os resultados evidenciaram uma correlação positiva entre a Fm e o torque extensor de joelho sendo que para o VM obteve-se $\mathrm{r}=0.87$ e para o $\mathrm{VL} \mathrm{r}=0.76$, assim o aumento do torque foi acompanhado pelo aumento da Fm. Também foi encontrado uma correlação negativa entre a proporção de fibras tipo I e o intercepto do Fm/torque, assim quanto maior a Fm menor era a proporção de fibras tipo I. De acordo com os resultados, os autores afirmam que a Fm do sinal eletromiográfico pode ser utilizada como um indicador do recrutamento de UM, uma vez que a Fm é dependente da força e tipo de fibra (56).

De acordo com a literatura, as UM são tipicamente recrutadas de maneira gradual e ordenada, das UM mais lentas e pequenas para as mais rápidas e grandes, numa rampa de contração isométrica (59). Por outro lado, a estimulação elétrica pode gerar o recrutamento reverso, sendo que a ordem de recrutamento das UM é das mais rápidas para as mais lentas $(60,61)$ e tais contrações podem ser comparadas com a baixa magnitude do reflexo de estiramento onde UM lentas são ativadas. Baseado nesta teoria, Walkeling, et al., (2004) (54) testou estes diferentes caminhos de recrutamento muscular para analisar as propriedades espectrais do sinal mioelétrico de diferentes UM. Para tanto, foram coletadas informações da contração isométrica gradual, do reflexo h e o reflexo de estiramento. Os resultados revelam 
que a estimulação elétrica pode resultar preferencialmente no recrutamento de UM rápidas, observadas pela presença de altas frequências e o inverso é observado no reflexo de estiramento. Durante a rampa de contração evidenciou-se que as UM são recrutadas na ordem de lentas para rápidas, uma vez que a análise tempo-frequência mostrou um aumento gradual em componentes de alta frequência com o aumento da força. Todos os experimentos demostraram componentes de alta frequência quando UM rápidas são assumidas como ativas (54).

O padrão de atividade muscular, por meio da análise do espectro de frequência, também foi analisado em atividades dinâmicas como a corrida. No estudo de Walkeling, et al., (2001) (51) os voluntários correram por 30 min e o sinal eletromiográfico foi coletado para vários músculos, dentre eles o RF. Os resultados evidenciaram uma significativa redução na intensidade EMG em baixas frequências e um significativo aumento em altas frequências durante a corrida. Os autores sugerem que o aumento na intensidade de componentes de alta frequência ocorreu com a diminuição na intensidade de componentes de baixa frequência. Os mecanismos que explicam estas mudanças não estão claros, mas os autores acreditam que o aumento da intensidade nas altas frequências está relacionado ao fato das fibras tipo II (rápida contração) serem mais suscetíveis à fadiga, ocorrendo um aumento do recrutamento destas fibras em particular durante a corrida sustentada. Em relação à diminuição da intensidade em baixas frequências, os autores (51) suspeitam de que exista uma possível inibição promovida pelas células de Renshaw. Estas células regulam a taxa de disparo das UM e são mais fortemente excitadas pelos motoneurônios colaterais grandes que pelas pequenas. Se a ação inibitória das células de Renshaw sobre os motoneurônios alfa é alcançado de uma forma relacionada ao tamanho, motoneurônios com diâmetro menor seriam mais afetadas que as largas, então este mecanismo complementário poderia preferencialmente diminuir o recrutamento das UM que já estavam ativas. 
Outro estudo muito interessante, investigou a relação entre o comportamento do espectro de frequência e os tipos de fibra em animais com características peculiares (55). O experimento foi realizado com peixes e gatos. O peixe foi escolhido pois os tipos de fibras são anatomicamente separados, permitindo o acesso individual das fibras. Já em vertebrados, como o gato, os diferentes tipos de fibra estão mixados dentro de cada músculo, sendo difícil coletar informações EMG de fibras isoladas, as quais são recrutadas de acordo com a demanda. As fibras rápidas e lentas do peixe geraram sinais mioelétricos com diferentes bandas de frequência. As fibras de contração lenta (fibras vermelhas) apresentaram intensidade espectral predominantemente em frequências muito baixas comparadas às fibras de contração rápida (brancas). Assim, fibras rápidas e lentas tem caraterística de alta e baixa banda de frequência na intensidade do espectro de potência. Componentes de baixa e alta frequência também ocorreram na intensidade do espectro do sinal mioelétrico do músculo gastrocnêmio de gatos, e a intensidade dentro destas bandas correspondeu a diferentes estratégias de recrutamento de UM lentas e rápidas, respectivamente, durante tarefas de locomoção (55). Por fim, Kupa et al, 1995 (57) encontrou forte correlação entre a Fmed e as porcentagens dos tipos de fibra. A correlação foi positiva e maior para as fibras rápidas e o parâmetro EMG (Fmed), apresentando $r=0.92$ para as glicolíticas (fibras de rápidas IIa e IIb), sendo que para a porcentagem de fibras tipo IIa apresentou $r=0.83$ e a porcentagem de fibras tipo IIb apresentou $r=0.90$. As fibras lentas (oxidativas) apresentaram uma correlação negativa com o parâmetro EMG (Fmed), $r=-0.91$. A velocidade de condução apresentou correlação positiva para as fibras glicolíticas $r=0.71$ e correlação negativa para as oxidativas $r=-0.78$ (57). Baseado nos estudos acima percebe-se que o comportamento do espectro de potência pode refletir nas estratégias de recrutamento muscular, mais especificamente no tipo de unidade motora ativada durante a contração muscular. 
No estudo da DFP a principal abordagem para a análise do sinal eletromiográfico é dada no domínio do tempo, sendo que o destaque é na avaliação dos onsets, tempo de início da ativação dos músculos VM e VL. Estudos neste âmbito buscam padronizar essas análises no domínio do tempo, porém não chegam a uma resposta em comum que consiga diferenciar um grupo normal de um grupo patológico (29,33-35). Como mencionado acima, alterações na ativação dos músculos vastos podem não ser justificadas por atrasos nas ativações do VM e VL $(29,33)$, mas evidenciadas por alterações dos parâmetros do domínio da frequência $(33,38,62)$. Ferrari et al. (2014) investigou parâmetros globais e específicos do espectro de potência em mulheres com DFP e assintomáticos durante a subida de escada (38). Neste estudo observou-se que o parâmetro global, a frequência mediana, não foi capaz de diferenciar os grupos, já os parâmetros específicos como a banda de baixa e média frequência apresentaram-se alteradas nos indivíduos com DFP. Outro estudo, também evidenciou alterações nos parâmetros específicos de análise da frequência, revelando que a banda de média frequência apresentou-se alterada para os músculos VM e VL de mulheres com DFP e a banda de alta frequência apresentou-se alterada apenas para o músculo VL do grupo DFP (33). Ambos estudos, não encontram diferença na Fmed, no entanto, destacam alterações nas bandas de frequência, evidenciando a existência de alterações na ativação destes músculos em mulheres com DFP. Apesar das alterações eletromiográficas no domínio da frequência serem evidentes em indivíduos com DFP, ainda é desconhecida a razão/motivo que leva a este padrão patológico e as possíveis inferências fisiológicas e clínicas destes achados. Uma alternativa para entender as repercussões dessas alterações eletromiográficas é associá-las às alterações cinéticas, como a LR. Analisar se parâmetros eletromiográficos encontram-se alterados no momento em que a LR ocorre, poderá auxiliar na compreensão de um possível mecanismo envolvido na DFP. 
Sabe-se que dentre as funções do músculo esquelético destacam-se a absorção de impacto. Para tanto, é crucial que a função do sistema neuromuscular esteja intacta, para agir como atenuador da força de reação do solo e das LR (63) e consequentemente, promover a proteção dos membros inferiores e corpo contra lesões relacionadas à absorção de impacto $(44,63,64)$. Cabe destacar que um importante parâmetro para avaliar a sobrecarga dos tecidos musculoesqueléticos do membro inferior é a LR. A literatura mostra que altas LR apresentam associação com fraturas de tíbia por estresse (65), DFP (66), fasceíte plantar (67), e osteoartrite de joelho (45). Dessa forma, considerando que o mecanismo de absorção de impacto, promovida pelo músculo quadríceps, possa estar comprometido em indivíduos com DFP, torna-se relevante investigar se existe relação entre as alterações eletromiográficas e a LR. O entendimento sobre este processo, poderá contribuir para o desenvolvimento de estratégias de tratamento e prevenção da DFP.

\subsection{CONSIDERAÇÕES SOBRE CAPACIDADE DISCRIMINATÓRIA E FATOR DE} RISCO

A DFP, como mencionado anteriormente, apresenta alta prevalência acometendo 1 a 4 indivíduos fisicamente ativos (4) entre as idades de 16 a 25 anos (4). Sabe-se que a dor característica desta patologia é exacerbada durante a realização de atividades cotidianas como subir e descer escadas, agachamentos, permanecer sentado por tempo prolongado (2), gerando limitações funcionais ao indivíduo e prejudicando de maneira significativa a execução de práticas esportivas (68). Além disso, a DFP pode estar associada com o desenvolvimento de patologias de maior grau de limitação funcional como, já citada, a osteoartrite patelofemoral $(6,7)$. 
Neste contexto, ressalta-se a importância de um diagnóstico clínico precoce para intervir na evolução desta desordem. Entretanto, estudos relacionados ao desenvolvimento de ferramentas clínicas para caracterização e/ou diagnóstico da DFP constitui uma temática ainda muito pouco explorada na literatura. Segundo Cook et al (2010) faz 25 anos que o termo síndrome da dor femoropatelar (sinônimo de DFP) é utilizado, porém são pouquíssimos os estudos que examinaram de forma explícita a capacidade discriminatória dos testes clínicos utilizados para diagnosticar a DFP. Curiosamente, estes estudos foram publicados a partir de 2001, significando que a investigação da sensibilidade, especificidade e reprodutibilidade dos componentes de uma ferramenta clínica para a caracterização da DFP constitui um esforço relativamente novo (69).

Nijs e colaboradores (2006) se dedicaram a investigação da acurácia diagnóstica de alguns testes físicos, e concluíram que a validade dos testes, comumente utilizados para diagnóstico, como o de Waldron, Clarke, de apreensão, de coordenação do vasto medial e eccentric step são questionáveis, pois apresentaram valores de razão de verossimilhança positiva baixos e negativa altos, muito distantes do ideal para considerar um teste válido para diagnóstico (70). Em outro estudo, realizado por Cook e colaboradores (2010), observou-se que os testes de compressão da patela contra o fêmur durante contração isométrica do quadríceps, palpação das bordas da patela, contração resistida do quadríceps, agachamento, subir escadas, ajoelhado e sentado por tempo prolongado, quando analisados de forma isolada apresentaram valores de verossimilhança positiva baixos. Contudo, ao analisar uma combinação de testes físicos com os testes funcionais observou-se uma melhora nos valores de verossimilhança positiva, principalmente quando se agregou os testes de contração resistida, palpação das bordas da patela e agachamento (69).

Atualmente, não existe um padrão ouro para o diagnóstico da DFP, entretanto há uma variedade de referências padrão aceitáveis para tal, como a artroscopia, exames de imagem, 
testes clínicos associados a perdas funcionais e a presença de dor anterior ao joelho que se reproduz durante a realização de atividades de agachamento, subir e descer escadas, permanecer muito tempo sentado, dentre outras. Acredita-se que esta variedade de referências padrão prejudica a qualidade metodológica dos estudos e ainda, provoca uma ampla variação estatística dos testes positivos para a DFP (71). Somando-se a isto, existe uma insuficiência de evidências que determinam a reprodutibilidade, validade, sensibilidade e especificidade de exames de imagem que indiquem, por exemplo, a congruência angular, deslocamento patelar lateral, inclinação patelar, dentre outras alterações que possam ocorrer nos indivíduos com DFP (72). Assim como os exames de imagem, os testes funcionais e clínicos, também apresentam uma investigação limitada da acurácia diagnóstica (69).

A causa multifatorial da DFP, também é um fator que dificulta a identificação de um padrão ouro para caracterização e/ou diagnóstico da DFP. Diante disso, pesquisadores lançaram uma nova abordagem na tentativa de encontrar um parâmetro que seja capaz de discriminar acuradamente indivíduos com e sem dor. Neste contexto, parâmetros biomecânicos alterados em indivíduos com DFP foram testados e revelaram valores de acurácia diagnóstica superiores aos observados para testes clínicos e funcionais $(23,33,38)$. Oliveira et al, investigou a capacidade discriminatória da eversão do retropé no gesto de subida de escadas e revelou $72 \%$ de sensibilidade e $69 \%$ de especificidade. Parâmetros eletromiográficos, relacionados às alterações de controle neuromotor dos músculos VM e VL nos indivíduos com DFP, também foram investigados quanto à capacidade discriminatória. Briani et al, investigou parâmetros do domínio do tempo e da frequência do sinal eletromiográfico coletado durante a descida de escada. No domínio do tempo foi investigado o onset dos músculos VM e VL por meio de três técnicas de processamento, no entanto, nenhum resultado significativo de sensibilidade e especificidade foi encontrado. Os parâmetros do domínio da frequência, frequência mediana e bandas de frequência, também 
foram analisados e apresentaram uma capacidade discriminatória relevante. Dentre os parâmetros analisados a banda de média frequência $(45$ a $96 \mathrm{~Hz})$ do músculo VM apresentou os melhores valores de sensibilidade e especificidade, $72 \%$ e $69 \%$ respectivamente (33). Em outro estudo, a banda de média frequência foi investigada na subida de escada e apresentou $87 \%$ de especificidade e $70 \%$ de sensibilidade (38). Os valores superiores de sensibilidade e especificidade observados no estudo de Ferrari et al (2014), quando comparado com Briani et al (2015), podem ser explicados pelas diferenças metodológicas. No estudo de Ferrari et al (2014) a capacidade discriminatória foi baseada no intervalo do sinal eletromiográfico, assim, pacientes que apresentavam valores eletromiográficos dentro do intervalo especificado eram considerados saudáveis e indivíduos que apresentavam valores fora desse intervalo eram considerados com DFP. Já no estudo de Briani, et al. (2015) foi definido um ponto de corte, por meio da curva ROC (Receiver Operating Characteristic) para determinar quem era saudável e quem tinha DFP. Além disso, o gesto em que os sinais eletromiográficos foram coletados eram diferentes, no primeiro estudo (38) o gesto estudado foi a subida de escada, enquanto o segundo (33) foi a descida. Observa-se que apesar das diferenças metodológicas descritas nos estudos de Ferrari et al (2014) e Briani et al. (2015) a banda de média frequência, parâmetro que representa um comportamento mais específico do espectro de potência do sinal eletromiográfico, apresentou valores superiores de sensibilidade e especificidade, quando comparado à um parâmetro global como a frequência mediana.

Nota-se que os parâmetros biomecânicos investigados, principalmente a banda de média frequência, apresentaram os melhores valores de acurácia diagnóstica já reportados na literatura. Além disso, os resultados demonstraram um equilíbrio entre os valores de sensibilidade e especificidade, atendendo as recomendações da literatura (73). No entanto, sabe-se que quanto maior os valores de sensibilidade e especificidade, melhor a capacidade da ferramenta em discriminar um indivíduo doente daquele saudável. Dessa forma, entende-se 
que os valores de sensibilidade e especificidade destes parâmetros devem ser maiores para evitar caracterizações equivocados. Dessa forma, acredita-se que um processamento diferenciado pode melhorar estes resultados. Neste contexto, o presente estudo pretende analisar o sinal eletromiográfico de duas maneiras: i) analisar o sinal eletromiográfico correspondente à Fz, e ii) analisar o sinal eletromiográfico correspondente à LR da Fz.

Baseado em estudos prévios, a banda de média frequência, apresentou a melhor capacidade discriminatória dentre os parâmetros biomecânicos analisados na DFP $(33,38)$. Entretanto, observa-se que ela não é $100 \%$ sensível ou específica, revelando a presença falsos positivos e negativos. No estudo de Ferrari, et al. 2014, $13 \%$ das mulheres com DFP não apresentam alterações eletromiográficas e 30\% das mulheres assintomáticas apresentam. Interessantemente, no estudo de Briani et al, 2015, 28\% das mulheres com DFP não apresentaram alterações eletromiográficas e $31 \%$ das mulheres assintomáticos apresentaram alterações. Percebe-se que mulheres com e sem dor compartilham das mesmas alterações, mas obviamente diferem na dor. Frente a estes achados, surge a dúvida: será que a ferramenta é adequada para discriminar as mulheres com e sem DFP ou será que os falsos positivos/negativos têm uma propensão a melhorar/desenvolver DFP? Neste contexto, é relevante monitorar mulheres com e sem alteração eletromiográfica ao longo do tempo para observar o surgimento ou melhora da dor. Identificar um padrão eletromiográfico que possa ser considerado um fator de risco para a DFP é de suma importância para determinação de medidas preventivas. 


\section{MATERIAL E MÉTODOS}

\subsection{DELINEAMENTO EXPERIMENTAL}

O presente estudo foi constituído de análises baseadas em modelos experimentais, os quais foram fundamentados na metodologia exposta e discutida neste item. $O$ fluxograma apresentado na Figura 1 representa, resumidamente, as etapas do protocolo elaborado para atendimento dos propósitos científicos do trabalho.

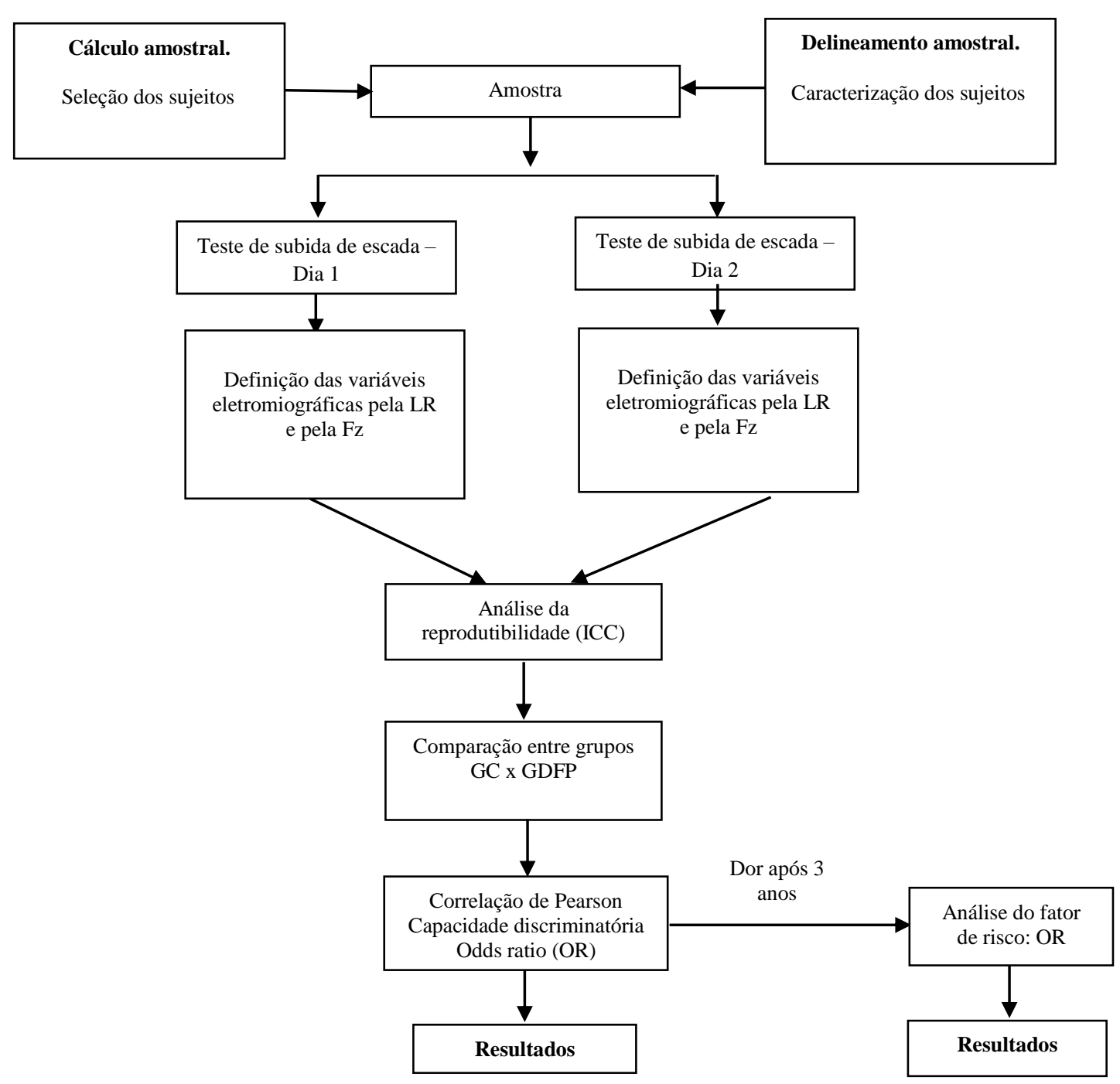

Figura 1 - Fluxograma representando o delineamento experimental do estudo 


\subsection{DESENHO EXPERIMENTAL}

Este estudo ocorreu em dois momentos e, portanto, pode ser caracterizado como observacional transversal e longitudinal. Primeiramente, foram analisados os parâmetros eletromiográficos quanto a sua reprodutibilidade, precisão, capacidade discriminatória, correlação com a dor, acurácia diagnóstica e possível fator de risco, caracterizando um estudo transversal. Em um segundo momento, foi analisada a associação entre as mulheres expostos/não expostos às alterações eletromiográficas com a dor reportada após três anos da primeira avaliação, caracterizando um estudo longitudinal.

\subsection{AMOSTRA}

O cálculo amostral foi realizado baseado em um estudo piloto desenvolvido previamente às coletas de dados. Optou-se pelos resultados dos parâmetros com maior desvio padrão e maior diferença a ser detectada (74). Para um teste com poder de $80 \%(1-\beta=0.80)$ e $\alpha=0.05$, bicaudal, o tamanho da amostra calculado foi de 38 mulheres em cada grupo. Um segundo cálculo amostral foi realizado para analisar a associação entre a variável dor e as variáveis EMG. Considerou-se para este cálculo o poder de $80 \%$ e $\alpha=0.05$ com $r=0.60$, resultando numa amostra de 20 mulheres por grupo. Considerando os dois cálculos amostrais, optou-se por uma amostra de 80 mulheres as quais foram divididas em dois grupos: i) o grupo controle composto por 40 mulheres com idade média de $21.54 \pm 3.10$ anos, peso médio de $57.49 \pm 8.83 \mathrm{Kg}$ e altura média de $1.63 \pm 0.06 \mathrm{~m}$; e ii) o grupo DFP composto por 40 mulheres com idade média de $22.59 \pm 2.19$ anos, peso médio de $60.81 \pm 10.40 \mathrm{Kg}$ e altura média de $1.64 \pm 0.05 \mathrm{~m}$. A amostra foi recrutada nos cursos de graduação e pós-graduação da Universidade Estadual Paulista “Júlio de Mesquita Filho" Faculdade de Ciências e Tecnologia 
(FCT/UNESP), também foram distribuídos anúncios em academias e parques das cidades de Presidente Prudente - SP. As mulheres que concordaram em participar da pesquisa assinaram o termo de consentimento livre e esclarecido, elaborado de acordo com a resolução 196/96 do Conselho Nacional de Saúde. A execução desta pesquisa foi aprovada pelo comitê de Comitê de Ética em Pesquisa da Universidade Estadual Paulista "Júlio de Mesquita Filho" Faculdade de Ciências e Tecnologia (FCT/UNESP), campus de Presidente Prudente, sob o número 31880814.30000.5402 (ANEXO A).

Para seleção da amostra utilizou-se os seguintes critérios de inclusão e exclusão:

a) Critérios de inclusão (ambos os grupos): foi aplicado por três fisioterapeutas formados e treinados um protocolo de avaliação clínica (ANEXO B). Este protocolo foi pontuado e as mulheres que exibiram pontuação $\geq 4$ foram considerados positivos para a DFP enquanto que as mulheres que apresentaram pontuação < 4 foram consideradas saudáveis. Para ser incluído no grupo DFP e consequentemente participar da pesquisa, dois fisioterapeutas deveriam concordar quanto a pontuação atingida no final do protocolo $(\geq 4)$ e para ser incluído no grupo controle três fisioterapeutas deveriam apresentar diagnósticos negativos para a DFP (pontuação < 4).

b) Critérios de exclusão: foram excluídas do grupo DFP mulheres com qualquer sinal ou sintoma de outra desordem no joelho que não fosse DFP e foram excluídas do grupo controle mulheres com qualquer sinal ou sintoma de desordem no joelho. Para ambos os grupos, foram excluídas as mulheres com história recente (dentro de três meses) de cirurgia no membro inferior, história de subluxação patelar ou uma evidência clínica de lesão meniscal, instabilidade ligamentar, osteoartrose, patologia no tendão patelar, ou dor referida vinda da espinha; presença de doença neurológica; presença de processo inflamatório; fisioterapia prévia (pelo menos 6 meses). 


\subsubsection{Protocolo de avaliação clínica}

A ferramenta clínica utilizada neste estudo (ANEXO B) foi composta por três dimensões: i) sintomas relacionados à presença de dor; ii) limitações funcionais; iii) testes clínicos específicos para caracterizar a presença da DFP. No total estas dimensões englobam 16 ações, dividas em escalas de dor e testes clínicos mais utilizados como critérios de inclusão de mulheres com DFP nos estudos da área $(23,38,70,75)$. Na primeira questão do protocolo utilizou-se uma escala visual analógica (EVA) de $10 \mathrm{~cm}$ para quantificar a pior dor sentida no joelho no último mês. Esta ferramenta é validada, reprodutível e responsiva para mulheres com DFP (76).

\subsection{INSTRUMENTAÇÃO}

\subsubsection{Escada de teste}

Este projeto faz parte de uma linha de pesquisa desenvolvida no LABCOM e, portanto, a escada que foi utilizada neste projeto é a mesma que foi utilizada em outras pesquisas (FAPESP 2010/06833-6 e 2011/04808-7) (23,33,38). A escada foi elaborada para possibilitar a execução do gesto de subida o mais próximo possível do funcional. As dimensões obedecem às normas propostas pela NBR 9077/2012, sendo assim a escada foi confeccionada em base de madeira, com sete degraus de $18 \mathrm{~cm}$ de altura, $28 \mathrm{~cm}$ de profundidade e com largura de 1m, com um corrimão para propiciar segurança as voluntárias; a plataforma de força foi alocada no quarto degrau (Figura 2). Antes do primeiro degrau e após o último, existe uma passarela de $2 \mathrm{~m}$ para que as voluntárias iniciem e terminem o movimento com uma breve caminhada. 


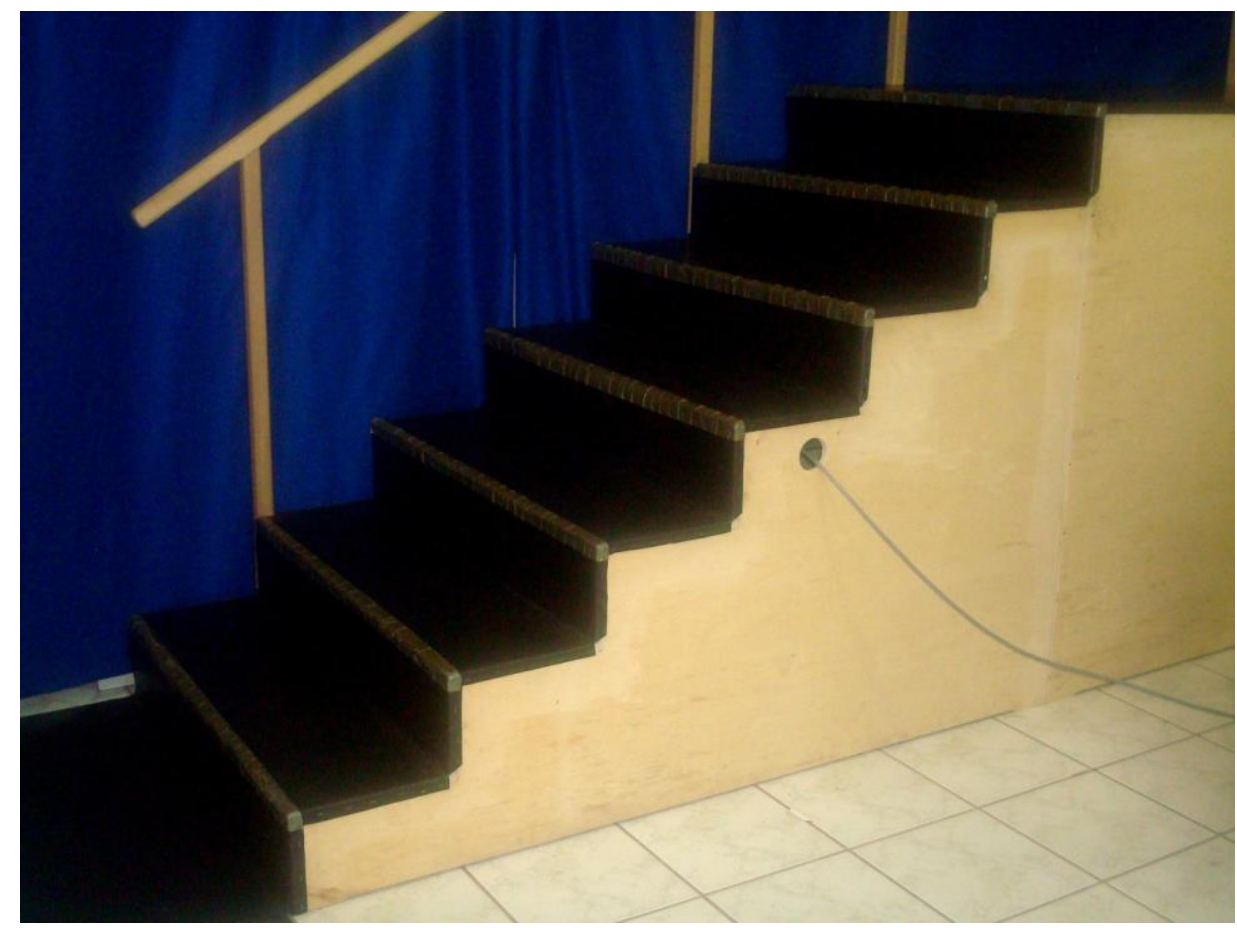

Figura 2 - Escada utilizada para a realização do gesto de estudo

\subsubsection{Eletromiografia e plataforma de força}

Para a aquisição do sinal eletromiográfico foram utilizados 2 pares de eletrodos de superfície, modelo Meditrace ${ }^{\circledR}$ da marca $3 \mathrm{M} \circledast$, com superfícies de captação de $\mathrm{Ag} / \mathrm{AgCl}$ com 10mm de diâmetro. Os eletrodos foram posicionados paralelamente, separados entre si por 20mm. O equipamento apresentava um circuito pré-amplificador com ganho de 20 vezes, CMRR (Common Mode Rejection Ratio) maior que $80 \mathrm{~dB}$ e impedância de $1012 \Omega$.

A plataforma de força utilizada era da marca Bertec (Bertec Corporation, Columbus, OH) modelo FP4060. Ela foi acoplada no quarto degrau da escada de teste de maneira não visível às voluntárias. Os sinais foram sincronizados e captados em um módulo condicionador de sinais da marca LYNX®, modelo ADS 1000 - AC1160. Neste módulo dois canais para a aquisição de sinais EMG foram configurados com um filtro digital, passa-baixa com frequência de corte de $500 \mathrm{~Hz}$ e um passa-alta com frequência de corte de $20 \mathrm{~Hz}$. Também, foram configurados três canais para aquisição dos dados referentes as componentes, vertical e 
lateral, da força de reação do solo (FRS). Todos os canais apresentaram ganho final de 1000 e frequência de amostragem de $4000 \mathrm{~Hz}$. A aquisição e o armazenamento dos sinais em arquivos de dados foram feitos através do software Bioinspector 1.8, também da LYNX®.

\subsubsection{Fixação dos eletrodos}

Antes da execução dos testes, os eletrodos para captação do sinal eletromiográfico foram fixados sobre as porções do VL e VM do músculo quadríceps femoral, a partir da localização do ponto motor na região do ventre da porção muscular. Este procedimento foi realizado utilizando um aparelho de eletroestimulação da marca Quark®, modelo NeMESys 941 e um eletrodo tipo "caneta” (Figura 3). Após a localização e marcação do ponto, foi realizada a tricotomia e a limpeza da região. Os eletrodos foram posicionados a aproximadamente $2 \mathrm{~cm}$ do ponto motor na direção do ventre muscular (47).

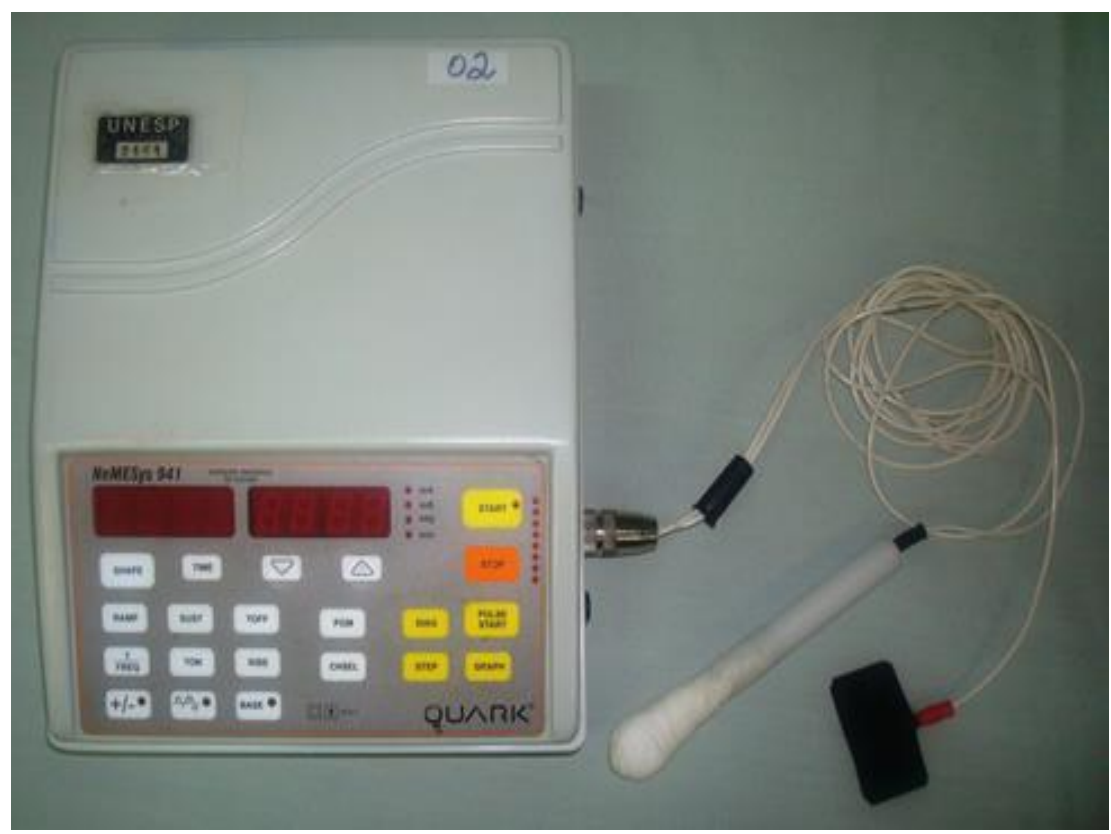

Figura 3 - Eletroestimulador utilizado para localização do ponto motor

Neste estudo, as coletas de dados foram realizadas em dois dias e para reduzir a variabilidade das medidas inerentes ao posicionamento dos eletrodos foi utilizado um sistema 
de gabarito referenciado por pontos anatômicos da patela e do quadril do sujeito. Os pontos motores foram identificados e posteriormente foram marcados em uma transparência sobreposta à coxa da voluntária. Os pontos de referência para o posicionamento da transparência foram: i) uma linha traçada entre o centro da patela e a espinha ilíaca anterosuperior e, ii) a borda superior da patela (Figura 4 e 5).

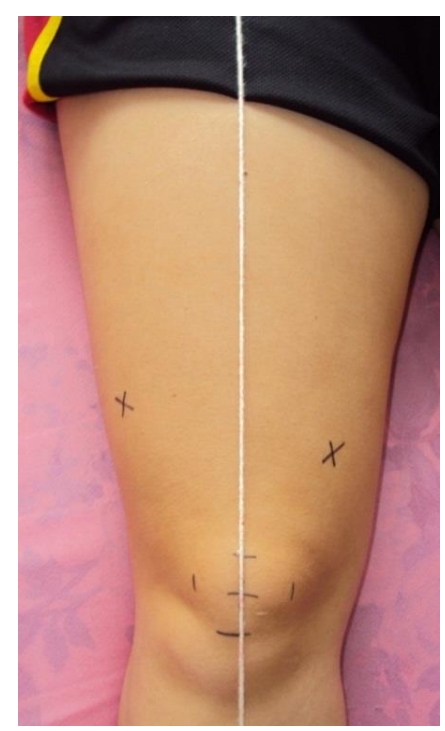

Figura 4 - Pontos de referência para o posicionamento da transparência

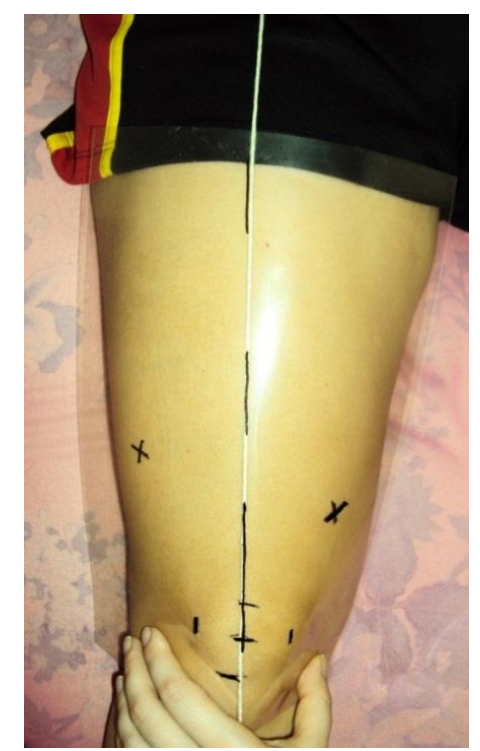

Figura 5 - Pontos de referência para o posicionamento da transparência 
No retorno da voluntária para uma nova seção de teste, bastou alinhar o gabarito (transparência) com a marcação da borda superior da patela e com o traço entre a espinha ilíaca antero-superior e o centro da patela. Após o correto alinhamento do gabarito a marcação dos pontos motores foi realizada e, posteriormente, foi preparada a pele da voluntária e os eletrodos foram fixados.

\subsection{PROCEDIMENTO EXPERIMENTAL}

Para o desenvolvimento desta pesquisa, as voluntárias compareceram no laboratório em dois dias distintos para a coleta dos dados eletromiográficos e cinéticos. Em um terceiro momento, 3 anos após a primeira coleta de dados, o pesquisador responsável entrou em contato com as voluntárias e aplicou a primeira pergunta do protocolo de avaliação. Assim, as voluntárias deveriam reportar se sentiram dor no joelho de início insidioso no último mês e quantificá-la ( a pior dor) de acordo com a EVA.

Antes da coleta de dados no laboratório, o ambiente e as voluntárias foram preparadas. O ambiente foi controlado em relação à temperatura, iluminação e organização dos instrumentos de medida. No primeiro dia de coleta, a voluntária foi orientada a vestir uma bermuda de ginástica para proporcionar a localização dos pontos motores dos músculos VM e VL, a fixação dos eletrodos na região definida e, posteriormente, a marcação dos pontos motores e dos pontos de referência na transparência. Em seguida, a voluntária era orientada a treinar a atividade de subir a escada, a fim de se familiarizar com o procedimento. Estando a voluntária segura para começar, foi dado início às coletas de dados.

As voluntárias foram orientadas a executar uma pequena caminhada até chegarem à escada e, a partir daí, de maneira contínua, subiram os degraus, com alternância dos membros inferiores, velocidade e ritmo autocontrolados, de maneira a assemelhar-se ao máximo à 
atividade habitual da voluntária. Ao final do último degrau continuaram o movimento com uma breve caminhada, num patamar que constituiu o último degrau. O movimento de subida foi repetido 10 vezes.

No segundo dia de coleta, as voluntárias retornaram ao laboratório, em um período máximo de uma semana e mínimo de 48 horas, para a repetição do teste descrito acima. Desta forma, foi possível calcular a reprodutibilidade das variáveis biomecânicas coletadas.

\subsection{PROCESSAMENTO DOS SINAIS EMG}

Os dados eletromiográficos e cinéticos foram processados por meio de um algoritmo desenvolvido em ambiente MatLab®. Os sinais eletromiográficos analisados foram referenciados pela componente vertical $(\mathrm{Fz})$ da FRS, fornecida pela plataforma de força. Este referenciamento foi realizado de duas maneiras: i) o sinal eletromiográfico analisado era correspondente à $\mathrm{Fz}$ completa, assim o começo e o final do sinal eletromiográfico era determinado pelo começo e final da Fz (Figura 6); ii) o sinal eletromiográfico analisado era correspondente à LR, assim o começo e o final do sinal eletromiográfico era determinado pelo começo e final da LR (Figura 7 e 8). O sinal eletromiográfico correspondente à LR está representado na Figura 7 entre as duas linhas vermelhas pontilhadas. A LR foi definida como a taxa entre $20 \%$ da Fz até o primeiro pico da componente vertical da força reação do solo (Figura 8). 


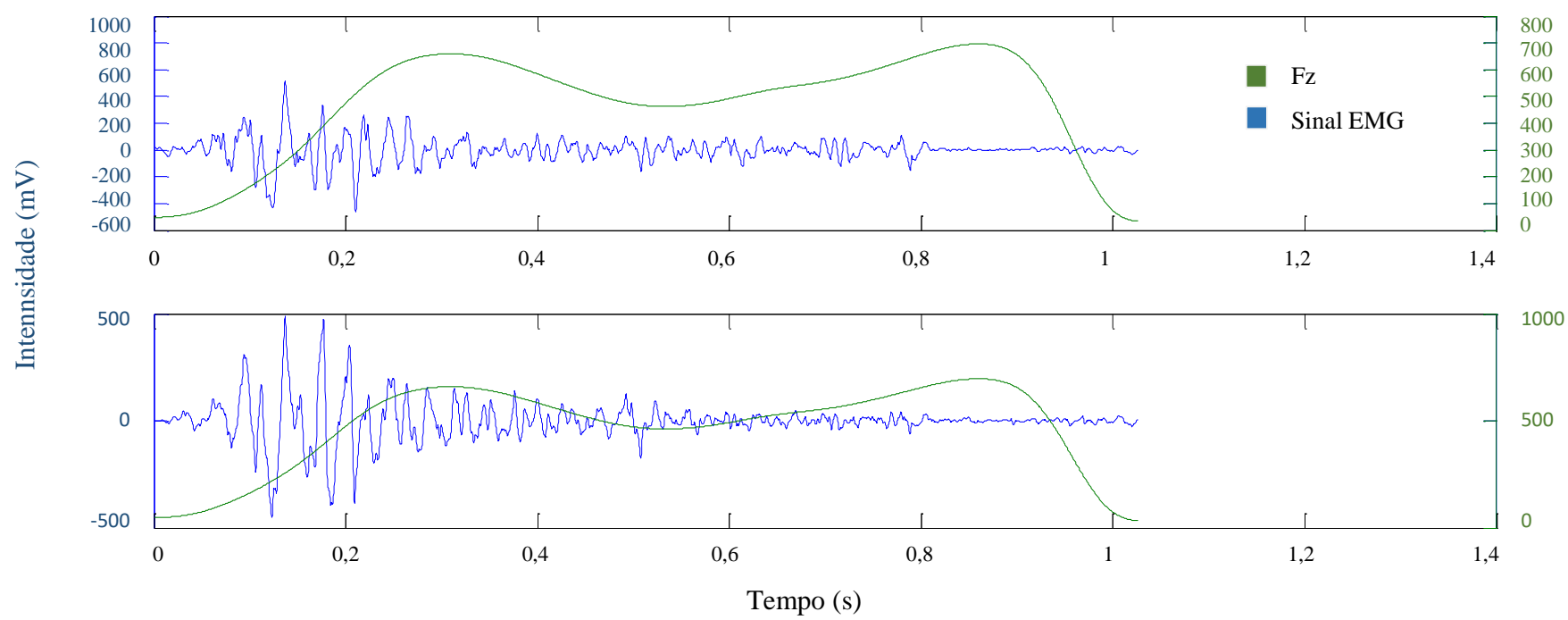

Figura 6 - Representação do sinal eletromiográfico referente à Fz

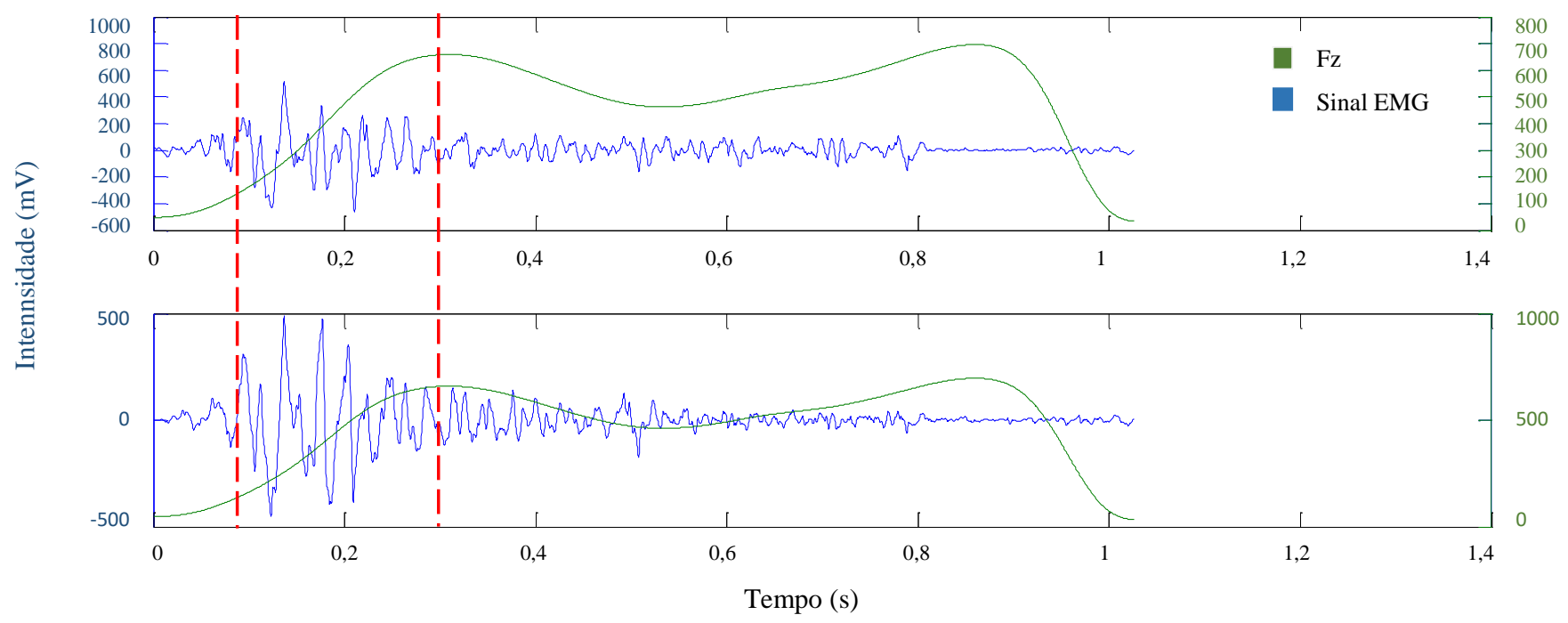

Figura 7 - Representação do sinal eletromiográfico referente à LR

Em seguida, os parâmetros EMG foram extraídos. A densidade do espectro de potência (PSD) das séries temporais do sinal eletromiográfico filtrado foi calculado pela TDF (77). A Fmed da PSD foi calculada como a frequência na qual as áreas do lado direito e esquerdo do espectro eram iguais (50). A intensidade da PSD foi normalizada de acordo com os seguintes passos: 1) cálculo da função de distribuição espectral, a qual é a soma cumulativa 
do espectro de potência dividido pelo seu valor máximo e multiplicado por 100; e 2) cálculo da derivada da função de distribuição espectral para obter a PSD com valores de intensidade normalizados entre 0 e 100 . Da PSD normalizada, a intensidade média foi calculada para cada uma das quatro bandas de frequência consideradas para análise: banda I (15 a 45Hz), banda II (45 a 96Hz), banda III (96 a 400Hz) e banda IV (10 a 30Hz) (38). No total foram extraídas a frequência mediana e quatro bandas de frequência (banda I, II, III e IV) para ambos os músculos, sendo que a banda IV foi calculada apenas quando o sinal eletromiográfico correspondente à LR. Optou-se por adicionar esta quarta banda, pois a frequência predominante da LR é entre 10 e $30 \mathrm{~Hz}$.

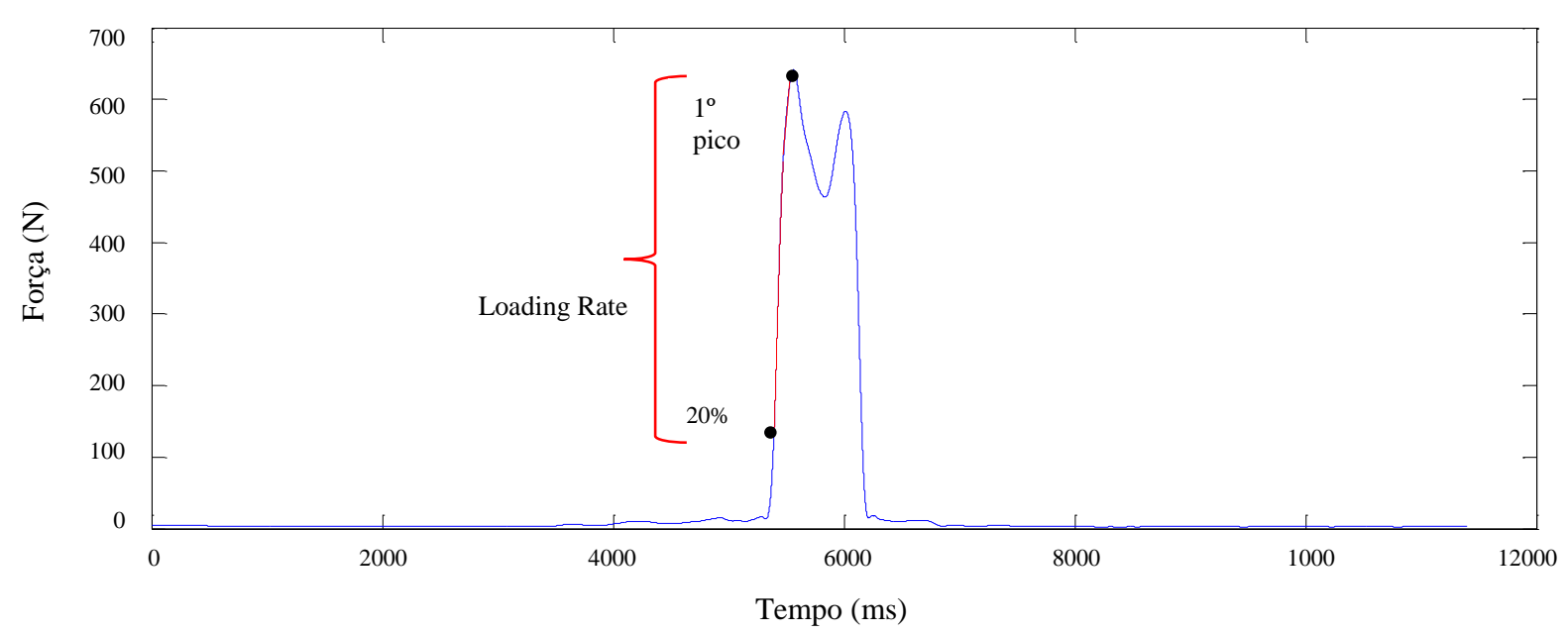

Figura 8 - Representação da LR

\subsection{ANÁLISE ESTATÍSTICA}

As análises estatísticas foram realizadas no software SPSS (Statistical Package for the Social Sciences) para Windows (versão 18.0). Realizou-se a análise estatística descritiva, média e desvio padrão, para as variáveis eletromiográficas (Fmed, banda I, II, II e IV) dos músculos VM e VL. A normalidade dos dados foi testada pelo Teste de Shapiro-Wilk. A reprodutibilidade dos dados foi investigada por meio de dois índices, o coeficiente de 
correlação intraclasse (ICC) com intervalo de confiança de 95\% (IC - 95\%) para expressar a reprodutibilidade relativa da medida e o erro padrão da medida (EPM) para expressar a reprodutibilidade absoluta da medida.

No presente estudo foi utilizado o $\mathrm{ICC}_{2, \mathrm{k}}$ (modelo two way random com concordância absoluta). Optou-se por este modelo, pois erros aleatórios e sistemáticos são considerados, permitindo que os dados obtidos possam ser generalizados para outros estudos $(74,78)$. Os valores considerados para descrever o grau de reprodutibilidade foram os mesmos utilizados nos estudos de Mathur 2005 e Kellis 2008 (79,80), onde: 0,00 a 0,25 - indicam pequena reprodutibilidade, 0,26 a 0,49 - pobre reprodutibilidade, 0,50 a 0,69 - indicam moderada reprodutibilidade, 0,70 a 0,89 - indicam alta reprodutibilidade e 0,90 a 1,00 - indicam reprodutibilidade muito alta.

O EPM foi calculado por meio da raiz quadrada da variância do erro, possuindo assim a mesma unidade de medida da variável testada. Valores baixos de EPM refletem uma maior reprodutibilidade das medidas, pois indicam sua precisão (81). O EPM normalizado foi calculado pela divisão do EPM absoluto pela média, entre os dois dias para os parâmetros avaliados, e multiplicados por 100 para obter a porcentagem da média.

As variáveis eletromiográficas foram comparadas entre os grupos por meio do Teste $t$ para amostras independentes. Para comparação entre os grupos foram utilizados os valores médios do "dia 1" e para o cálculo da reprodutibilidade foram utilizados os valores médios do "dia 2".

A correlação de Pearson foi realizada para investigar a associação entre a variável independente (variável eletromiográfica que diferenciou os grupos no Teste $t$ ) e a variável dependente (nível de dor e dor dicotomizada - presença ou ausência de dor). A correlação foi classificada como casual $(0-0.1)$, pequena $(0.1-0.3)$, moderada $(0.3-0.5)$, grande $(0.5-$ 0.7), muito grande $(0.7-0.9)$ e extremamente grande $(0.9-1.0)$ (82). As variáveis que 
apresentaram associação com a variável dor (nível de dor e dor dicotomizada), foram testadas quanto a sua capacidade de discriminar mulheres com DFP. Neste contexto, investigou-se a acurácia diagnóstica/discriminatória das variáveis eletromiográficas por meio da curva ROC (Receiver Operating Characteristic) e valores de sensibilidade, especificidade e área sob a curva (AUC) foram extraídos. Testes com valores de AUC maiores que 0.9 indicam alta acurácia, valores entre 0.7 e 0.9 indicam moderada acurácia, entre 0.5 e 0.7 indicam baixa acurácia e menor que 0.5 indicam acurácia casual $(73,83)$. Nesta análise, foi escolhido um ponto de corte em que os valores de sensibilidade e especificidade eram mais equilibrados, ou seja, o ponto da curva mais próximo de $(0,1)(73,74)$. Em seguida, este ponto de corte foi utilizado para classificar as mulheres que eram expostas ou não às alterações eletromiográficas.

Finalmente, para avaliar se as alterações eletromiográficas caracterizam-se como fatores de risco para DFP foi realizado o cálculo do Odds Ratio (OR) não ajustado. Este cálculo permite estimar o risco e, portanto, descreve a probabilidade que uma pessoa que está exposta à um determinado fator de risco irá ter a doença/desordem comparado a pessoas que não foram expostas ao mesmo fator. Neste contexto, calculou-se o OR para determinar a força da associação entre as mulheres expostos/não expostos às alterações eletromiográficas (variável independente) e a dor (variável dependente) reportada no dia e após 3 anos da avaliação eletromiográfica. O OR é indicado para este tipo de estudo uma vez que os participantes foram propositalmente escolhidos baseados na presença e ausência de desordem, além disso o OR não apresenta restrições quanto ao tipo de estudo $(74,83-86)$. 


\section{RESULTADOS}

Os resultados de reprodutibilidade são referentes à uma amostra de 20 voluntárias para cada grupo. Na tabela 1 encontram-se os resultados da estatística descritiva e de reprodutibilidade dos parâmetros do domínio da frequência do sinal eletromiográfico correspondente à $\mathrm{Fz}$ completa. Observa-se, de maneira geral, que a reprodutibilidade se mostrou alta com valores de ICC superiores a 0.73 para ambos os músculos e grupos. O EPM apresentou-se relativamente baixo, com exceção da banda III. Cabe ressaltar que quanto mais baixo o EPM, mais precisa é a medida.

Na tabela 2 apresentam-se os resultados descritivos e de reprodutibilidade dos parâmetros do domínio da frequência do sinal eletromiográfico correspondente à LR. A reprodutibilidade dos parâmetros eletromiográficos apresentaram-se altos com valores superiores à 0.80 . Além disso, o erro associado à medida apresentou valores baixos, com exceção da banda III que apresentou EPM relativamente alto. 
Tabela 1 - Valores descritivos e de reprodutibilidade dos parâmetros eletromiográficos correspondentes à Fz do grupo DFP e controle

\begin{tabular}{|c|c|c|c|c|c|c|c|c|c|c|}
\hline \multirow{2}{*}{ Parâmetros } & \multicolumn{5}{|c|}{ Grupo controle } & \multicolumn{5}{|c|}{ Grupo DFP } \\
\hline & $\begin{array}{c}\text { Dia } 1 \\
\mathrm{M} \pm \mathrm{DP}\end{array}$ & $\begin{array}{c}\text { Dia } 2 \\
\mathrm{M} \pm \mathrm{DP}\end{array}$ & $\mathrm{ICC}_{2 . \mathrm{k}}(\mathrm{IC} 95 \%)$ & EPM & $\mathrm{EPM}(\%)$ & $\begin{array}{c}\text { Dia } 1 \\
\mathrm{M} \pm \mathrm{DP}\end{array}$ & $\begin{array}{c}\text { Dia } 2 \\
\mathrm{M} \pm \mathrm{DP}\end{array}$ & $\mathrm{ICC}_{2 . \mathrm{k}}(\mathrm{IC} 95 \%)$ & EPM & EPM (\%) \\
\hline \multicolumn{11}{|l|}{ VM } \\
\hline Fmed & $51.94 \pm 6.96$ & $51.29 \pm 5.77$ & $0.81(0.52 ; 0.92)$ & 3.63 & 7 & $58.15 \pm 12.80$ & $56.69 \pm 8.08$ & $0.81(0.52 ; 0.92)$ & 6.09 & 10.6 \\
\hline Banda I (u.n) & $56.30 \pm 9.98$ & $55.93 \pm 7.43$ & $0.84(0.60 ; 0.93)$ & 4.62 & 8.2 & $46.82 \pm 12.12$ & $48.47 \pm 11$ & $0.84(0.61 ; 0.93)$ & 6.01 & 12.6 \\
\hline Banda II (u.n) & $28.58 \pm 5.14$ & $28.35 \pm 4.56$ & $0.86(0.65 ; 0.94)$ & 2.40 & 8.4 & $32.92 \pm 8.76$ & $33.18 \pm 8.30$ & $0.90(0.76 ; 0.96)$ & 3.61 & 10.9 \\
\hline Banda III (u.n) & $1.36 \pm 0.61$ & $1.37 \pm 0.52$ & $0.85(0.63 ; 0.94)$ & 0.28 & 20.5 & $1.87 \pm 1.28$ & $1.65 \pm 0.88$ & $0.61(0.03 ; 0.84)$ & 0.81 & 46 \\
\hline \multicolumn{11}{|l|}{ VL } \\
\hline Fmed & $55.86+12.86$ & $58.59+12.89$ & $0.81(0.54 ; 0.92)$ & 7.12 & 6.3 & $57.18 \pm 13.54$ & $56.97 \pm 10.64$ & $0.89(0.73 ; 0.95)$ & 5.37 & 9.4 \\
\hline Banda I (u.n) & $52.52 \pm 13.45$ & $49.88 \pm 12.84$ & $0.79(0.48 ; 0.91)$ & 7.72 & 15 & $47.69 \pm 11.63$ & $47.87 \pm 10.93$ & $0.73(0.30 ; 0.89)$ & 7.43 & 15.5 \\
\hline Banda II (u.n) & $26.44 \pm 4.79$ & $27.11 \pm 4.61$ & $0.74(0.35 ; 0.89)$ & 3.02 & 11.2 & $31.73 \pm 7.63$ & $31.83 \pm 8.09$ & $0.88(0.70 ; 0.95)$ & 3.66 & 11.5 \\
\hline Banda III (u.n) & $2.07 \pm 1.24$ & $2.32 \pm 1.21$ & $0.89(0.72 ; 0.95)$ & 0.52 & 23.7 & $1.88 \pm 1.38$ & $1.85 \pm 1.10$ & $0.89(0.72 ; 0.95)$ & 0.56 & 30.1 \\
\hline
\end{tabular}

Fmed - frequência mediana; Banda I - 15 - 45Hz; Banda II - 45 - 96Hz; Banda III - 96 - 400Hz; Banda IV - 10 - 30Hz; u.n - unidade normalizada; M - média aritmética;

DP - desvio padrão; EPM - erro padrão da medida; ICC - coeficiente de correlação intraclasse 
Tabela 2 - Valores descritivos e de reprodutibilidade dos parâmetros eletromiográficos correspondentes à LR do grupo DFP e controle

\begin{tabular}{|c|c|c|c|c|c|c|c|c|c|c|}
\hline \multirow{2}{*}{ Parâmetros } & \multicolumn{5}{|c|}{ Grupo controle } & \multicolumn{5}{|c|}{ Grupo DFP } \\
\hline & $\begin{array}{c}\text { Dia } 1 \\
M \pm D P\end{array}$ & $\begin{array}{c}\text { Dia } 2 \\
M \pm D P\end{array}$ & $\mathrm{ICC}_{2, \mathrm{k}}(\mathrm{IC} 95 \%)$ & EPM & EPM (\%) & $\begin{array}{c}\text { Dia } 1 \\
M \pm D P\end{array}$ & $\begin{array}{c}\text { Dia } 2 \\
M \pm \text { DP }\end{array}$ & $\mathrm{ICC}_{2, \mathrm{k}}(\mathrm{IC} 95 \%)$ & EPM & $\operatorname{EPM}(\%)$ \\
\hline \multicolumn{11}{|l|}{ VM } \\
\hline Fmed & $50.51 \pm 7.52$ & $48.76 \pm 7.57$ & $0.82(0.62 ; 0.91)$ & 4.08 & 8.22 & $54.17 \pm 10.28$ & $53.15 \pm 9.47$ & $0.93(0.84 ; 0.97)$ & 3.45 & 6.42 \\
\hline Banda I (u.n) & $57.36 \pm 11.44$ & $59.08 \pm 9.61$ & $0.87(0.73 ; 0.94)$ & 4.98 & 8.53 & $51.16 \pm 12.23$ & $51.91 \pm 12.72$ & $0.90(0.77 ; 0.96)$ & 5.24 & 10.16 \\
\hline Banda II (u.n) & $28.17 \pm 5.84$ & $27.26 \pm 5.29$ & $0.82(0.63 ; 0.91)$ & 3.02 & 10.89 & $31.68 \pm 8.28$ & $32.76 \pm 9.07$ & $0.93(0.84 ; 0.97)$ & 3.09 & 9.59 \\
\hline Banda III (u.n) & $1.27 \pm 0.76$ & $1.20 \pm 0.55$ & $0.90(0.79 ; 0.95)$ & 0.28 & 22.67 & $1.46 \pm 0.88$ & $1.19 \pm 0.66$ & $0.88(0.64 ; 0.95)$ & 0.31 & 23.39 \\
\hline Banda IV (u.n) & $43.20 \pm 11.24$ & $46.20 \pm 9.63$ & $0.87(0.71 ; 0.94)$ & 4.60 & 10.29 & $36.66 \pm 12.47$ & $38.32 \pm 13.69$ & $0.86(0.69 ; 0.94)$ & 6.35 & 16.93 \\
\hline \multicolumn{11}{|l|}{ VL } \\
\hline Fmed & $50.91 \pm 11.74$ & $50.91 \pm 11.74$ & $0.81(0.60 ; 0.91)$ & 6.59 & 12.94 & $53.49 \pm 10.43$ & $52.64 \pm 10.78$ & $0.93(0.85 ; 0.97)$ & 3.62 & 6.82 \\
\hline Banda I (u.n) & $57.77 \pm 13.85$ & $56.66 \pm 13.58$ & $0.80(0.58 ; 0.90)$ & 7.80 & 13.63 & $52.25 \pm 11.57$ & $52.31 \pm 12.38$ & $0.87(0.70 ; 0.94)$ & 5.74 & 10.97 \\
\hline Banda II (u.n) & $25.84 \pm 6.12$ & $26.12 \pm 5.88$ & $0.80(0.57 ; 0.90)$ & 3.47 & 13.35 & $31.07 \pm 7.04$ & $31.20 \pm 9.10$ & $0.90(0.77 ; 0.96)$ & 3.45 & 11.08 \\
\hline Banda III (u.n) & $1.53 \pm 1.09$ & $1.68 \pm 1.10$ & $0.91(0.81 ; 0.95)$ & 0.43 & 26.79 & $1.38 \pm 0.96$ & $1.29 \pm 0.99$ & $0.89(0.76 ; 0.95)$ & 0.42 & 31.46 \\
\hline Banda IV (u.n) & $45.20 \pm 13.86$ & $44.43 \pm 13.78$ & $0.82(0.62 ; 0.92)$ & 7.55 & 16.84 & $38.47 \pm 11.87$ & $40.72 \pm 14.61$ & $0.84(0.62 ; 0.93)$ & 6.97 & 17.60 \\
\hline
\end{tabular}

Fmed - frequência mediana; Banda I - 15 - 45Hz; Banda II - 45 - 96Hz; Banda III - 96 - 400Hz; Banda IV - 10 - 30Hz; u.n - unidade normalizada; M - média aritmética; DP - desvio padrão; EPM - erro padrão da medida; ICC - coeficiente de correlação intraclasse. 
Para realizar as comparações entre grupos, a análise de correlação e a acurácia diagnóstica considerou-se uma amostra de 80 voluntárias (grupo controle $=40$; grupo DFP $=$ 40) como descrito na metodologia. Na tabela 3 estão representados os resultados das comparações entre os grupos para as variáveis eletromiográficas correspondentes à Fz. Observa-se que a banda I e a banda II diferenciaram o grupo controle do grupo DFP para ambos os músculos com valores de $\mathrm{p}<0.03$.

Tabela 3 - Comparação entre grupo controle e DFP das variáveis eletromiográficas correspondentes à $\mathrm{Fz}$

\begin{tabular}{|c|c|c|c|}
\hline Parâmetros & $\begin{array}{c}\text { Grupo controle } \\
\text { (Média } \pm \text { Desvio Padrão) }\end{array}$ & $\begin{array}{c}\text { Grupo DFP } \\
\text { (Média } \pm \text { Desvio Padrão) }\end{array}$ & p-value \\
\hline \multicolumn{4}{|l|}{$\mathbf{V M}$} \\
\hline Fmed & $53.39 \pm 8.23$ & $56.39 \pm 10.51$ & 0.15 \\
\hline Banda I (u.n) & $52.74 \pm 9.86$ & $46.59 \pm 10.41$ & $0.009 *$ \\
\hline Banda II (u.n) & $30.42 \pm 6.59$ & $34.92 \pm 7.14$ & $0.005^{*}$ \\
\hline Banda III (u.n) & $1.44 \pm 0.68$ & $1.53 \pm 1.09$ & 0.65 \\
\hline \multicolumn{4}{|l|}{ VL } \\
\hline Fmed & $56.22 \pm 10.80$ & $57.76 \pm 10.89$ & 0.52 \\
\hline Banda I (u.n) & $50.41 \pm 11.60$ & $44.99 \pm 9.97$ & $0.03 *$ \\
\hline Banda II (u.n) & $28.73 \pm 5.88$ & $33.35 \pm 6.12$ & $0.001 *$ \\
\hline Banda III (u.n) & $1.99 \pm 1.04$ & $1.88 \pm 1.20$ & 0.62 \\
\hline
\end{tabular}

Na tabela 4 estão os resultados das comparações entre grupos para as variáveis eletromiográficas correspondentes à LR. Os resultados mostram que as bandas I, II e IV apresentam-se alteradas no grupo DFP, diferenciando os grupos $(\mathrm{p}<0.04)$. 
Tabela 4 - Comparação entre o grupo controle e DFP das variáveis eletromiográficas correspondentes à LR

\begin{tabular}{|c|c|c|c|}
\hline Parâmetros & $\begin{array}{c}\text { Grupo controle } \\
\text { (Média } \pm \text { Desvio Padrão) }\end{array}$ & $\begin{array}{c}\text { Grupo DFP } \\
\text { (Média } \pm \text { Desvio Padrão) }\end{array}$ & p-value \\
\hline \multicolumn{4}{|l|}{ VM } \\
\hline Fmed & $52.24 \pm 8.56$ & $53.71 \pm 8.70$ & 0.45 \\
\hline Banda I (u.n) & $53.68 \pm 12.36$ & $51.15 \pm 11.17$ & 0.34 \\
\hline Banda II (u.n) & $30.56 \pm 7.01$ & $32.94 \pm 7.59$ & 0.15 \\
\hline Banda III (u.n) & $1.28 \pm 0.81$ & $1.24 \pm 0.78$ & 0.82 \\
\hline Banda IV (u.n) & $40.37 \pm 11.92$ & $36.36 \pm 11.70$ & 0.13 \\
\hline \multicolumn{4}{|l|}{ VL } \\
\hline Fmed & $52.24 \pm 10.41$ & $55.07 \pm 9.68$ & 0.21 \\
\hline Banda I (u.n) & $54.37 \pm 13.25$ & $49.33 \pm 11.31$ & $0.04^{*}$ \\
\hline Banda II (u.n) & $28.36 \pm 6.98$ & $32.65 \pm 6.32$ & $0.00^{*}$ \\
\hline Banda III (u.n) & $1.51 \pm 0.95$ & $1.47 \pm 0.90$ & 0.84 \\
\hline Banda IV (u.n) & $42.0 \pm 13.21$ & $35.69 \pm 11.18$ & $0.02 *$ \\
\hline
\end{tabular}

Na tabela 5 e 6 estão representados os resultados da associação entre a variável dor (nível de dor e dor dicotomizada) e as variáveis eletromiográficas correspondentes à Fz e a LR, respectivamente. A valor médio de dor para o grupo DFP foi de $5.46 \pm 1.40$, avaliado com a EVA (10cm). Lembrando que estas associações só foram testadas para as variáveis que se mostraram alteradas na comparação entre grupos (tabela 3 e 4). Observa-se na tabela 5 moderada/fraca correlação negativa entre a banda I do músculo VM e VL e os níveis de dor (p $<0.01$ ), assim quanto menor a intensidade nesta banda de frequência, maior é a dor reportada pelo paciente. Resultados similares foram encontrados para a banda I e a dor dicotomizada, onde baixas intensidades na banda I estão associadas com a presença de dor. Nesta mesma tabela, observou-se uma correlação positiva entre a banda II dos músculos VL e VM e a dor (r $=0.61, \mathrm{p}<0.00$ ), assim quanto maior a intensidade na banda de frequência, maior é a dor reportada pelo paciente. Também, observou-se correlação positiva entre a banda II dos mesmos músculos e a variável dor dicotomizada, a qual evidencia que altas intensidades na banda II estão associadas com a presença de dor. 
Tabela 5 - Associação entre a variável dor e as variáveis eletromiográficas correspondentes à Fz

\begin{tabular}{|c|c|c|}
\hline Parâmetros & r (Pearson Correlation) & p-value \\
\hline \multicolumn{3}{|l|}{ VM } \\
\hline Banda I vs nível de dor & -0.33 & $0.003^{*}$ \\
\hline Banda I vs dor (dicotômica) & -0.31 & $0.005^{*}$ \\
\hline Banda II vs nível de dor & 0.40 & $0.000 *$ \\
\hline Banda II vs dor (dicotômica) & 0.42 & $0.000^{*}$ \\
\hline \multicolumn{3}{|l|}{ VL } \\
\hline Banda I vs nível de dor & -0.28 & $0.01 *$ \\
\hline Banda I vs dor (dicotômica) & -0.26 & $0.01 *$ \\
\hline Banda II vs nível de dor & 0.55 & $0.000^{*}$ \\
\hline Banda II $v s$ dor (dicotômica) & 0.61 & $0.000^{*}$ \\
\hline
\end{tabular}

Na tabela 6, observa-se uma correlação positiva entre a banda II do músculo VL e os níveis de dor, logo quanto maior a intensidade da banda de frequência maior é o nível de dor. Correlação positiva, também foi observada entre a banda II do músculo VL e a variável dor dicotomizada evidenciando que altas intensidades da banda II estão associadas com a presença de dor. Ainda, observou-se uma correlação negativa entre a banda IV e a variável dor dicotomizada, revelando que baixas intensidades na banda I estão associadas com a presença de dor $(\mathrm{p}<0.02)$.

Tabela 6 - Associação entre a variável dor e as variáveis eletromiográficas correspondentes à LR

\begin{tabular}{lccc}
\hline Parâmetros & r (Pearson Correlation) & & p-value \\
\cline { 1 - 1 } Banda I $\boldsymbol{v} \boldsymbol{s}$ nível de dor & -0.17 & 0.12 \\
Banda I $\boldsymbol{v} \boldsymbol{s}$ dor (dicotômico) & -0.20 & 0.07 \\
Banda II $\boldsymbol{v}$ s nível de dor & 0.24 & $0.03^{*}$ \\
Banda II $\boldsymbol{v}$ s dor dicotômico & 0.31 & $0.005^{*}$ \\
Banda IV $\boldsymbol{v}$ s nível de dor & -0.21 & 0.06 \\
Banda IV $\boldsymbol{v}$ s dor dicotômico & -0.25 & $0.02^{*}$ \\
\hline
\end{tabular}

Nível de dor - varia de 0 a 10 na escala visual analógica; dor dicotômico - presença ou ausência de dor; Banda I - 15 - 45Hz; Banda II - 45 - 96Hz; Banda IV - 10 - 30Hz; 
Os resultados da capacidade discriminatória, que foi avaliada apenas para os parâmetros que apresentaram correlação com a dor (tabela 5 e 6), estão descritos na tabela 7. Os parâmetros eletromiográficos correspondentes à LR apresentaram acurácia baixa (AUC < 0.67) com valores baixos de sensibilidade e/ou especificidade. Resultados similares foram encontrados para a banda I (correspondente à $\mathrm{Fz}$ ) dos músculos VM e VL, os quais evidenciaram acurácia baixa (AUC <0.67). Resultados positivos foram encontrados para a banda II (correspondente à Fz) dos músculos VM e VL, os quais apresentaram acurácia moderada (AUC > 0.78). O parâmetro que apresentou acurácia mais elevada foi a banda II do músculo VL (correspondente à Fz) com $\mathrm{AUC}=0.87$ e sensibilidade e especificidade de 0.82 e 0.80 , respectivamente.

Tabela 7 - Valores de acurácia discriminatória dos parâmetros eletromiográficos

\begin{tabular}{|c|c|c|c|c|}
\hline Parâmetros & AUC & Sensibilidade & Especificidade & Cutt-off \\
\hline \multicolumn{5}{|l|}{ EMG (Fz) } \\
\hline Banda I (u.n) - VM & $0.67(0.54 ; 0.79)$ & 0.71 & 0.61 & 50.24 \\
\hline Banda II (u.n) - VM & $0.78(0.67 ; 0.88)$ & 0.71 & 0.70 & 31.68 \\
\hline Banda I (u.n) - VL & $0.63(0.51 ; 0.76)$ & 0.65 & 0.58 & 48.32 \\
\hline Banda II (u.n) - VL & $0.87(0.79 ; 0.95)$ & 0.82 & 0.80 & 32.14 \\
\hline \multicolumn{5}{|l|}{ EMG (LR) } \\
\hline Banda I - VL & $0.59(0.47 ; 0.72)$ & 0.65 & 0.50 & 53.02 \\
\hline Banda II - VL & $0.67(0.56 ; 0.79)$ & 0.67 & 0.37 & 30.80 \\
\hline Banda IV - VL & $0.64(0.51 ; 0.76)$ & 0.65 & 0.55 & 39.74 \\
\hline
\end{tabular}

$\mathrm{Na}$ análise entre a associação do fator de risco "alterações eletromiográficas (altas intensidades na banda II) " e a presença de dor no dia e após três anos da avaliação eletromiográfica, evidenciaram que a variável testada (Banda II do VL) pode ser considerada fator de risco para a DFP. Os resultados da associação entre o fator de risco e a dor no dia da avaliação, evidenciaram que $36 \%$ das mulheres expostas ao fator de risco apresentaram dor e 
$13 \%$ não. O OR não ajustado evidenciou que mulheres expostas a alteração eletromiográfica tem 6.15 (2.33 a 16.21) vezes mais chance de ter dor que aquelas sem alterações eletromiográficas na banda II do músculo VL $(\mathrm{p}<0.0002)$.

Após três anos da avaliação inicial $45 \%$ das mulheres controles apresentaram dor, e 25\% das mulheres previamente classificadas com DFP não apresentaram dor. A associação do fator de risco e a presença de dor após três anos da avaliação eletromiográfica, mostrou que $80 \%$ das mulheres expostas tiveram dor e $47.1 \%$ das mulheres não expostos apresentaram dor. O OR não ajustado evidenciou que mulheres expostas à alteração eletromiográfica, mais especificamente intensidades altas (>32.14) na banda II, tem 4.50 (1.46 a 13.78) vezes mais chance de ter dor no futuro que aquelas que tem intensidade baixa na banda II do músculo VL $(\mathrm{p}=0.007)$ 


\section{DISCUSSÃO}

\subsection{REPRODUTIBILIDADE}

Avaliar a reprodutibilidade de uma ferramenta de teste é de suma importância para clínicos e pesquisadores, uma vez que o índice de reprodutibilidade permite estabelecer o grau de estabilidade exibida quando uma mensuração é repetida sob condições idênticas, em outros termos, a reprodutibilidade refere-se ao grau pelo qual os resultados obtidos por uma mensuração podem ser reproduzidos (87). A reprodutibilidade é fundamental para todos os aspectos de medição, porque sem ela não se pode ter confiança nos dados coletados, nem extrair conclusões racionais sobre estes dados (74). Neste contexto, o sinal eletromiográfico foi testado quanto a sua reprodutibilidade e precisão e os resultados mostraram alta e muito alta reprodutibilidade com baixo erro associado à medida para ambos os processamentos de dados, músculos e grupos.

Vários fatores podem alterar o espectro de potência e, possivelmente afetar a reprodutibilidade e precisão dos sinais eletromiográficos, estes incluem mudanças na temperatura, alterações no recrutamento muscular, tipos de fibras, profundidade e localização das fibras do músculo em relação ao eletrodo, estado metabólico local, interação entre a pele e o eletrodo, condições ambientais do local do experimento, reposicionamento de eletrodos e movimentação dos mesmos durante atividades dinâmicas $(47,88)$. Apesar de todos estes fatores, os parâmetros da frequência do sinal eletromiográfico mostraram-se altamente reprodutíveis e precisos. Cabe salientar, que alguns cuidados metodológicos foram considerados para minimizar estes efeitos: a pele foi adequadamente preparada antes da fixação dos eletrodos e os eletrodos de captação foram posicionados no ventre muscular entre a junção miotendínea e próximo a zona de inervação, localizada por meio da estimulação elétrica. Para tanto, utilizou-se um estimulador elétrico para localizar o ponto motor segundo 
as recomendações de De Luca, 1997 (47). A padronização dos experimentos é recomendada para reduzir os erros do sinal eletromiográfico e otimizar a reprodutibilidade e precisão (77). No presente estudo, foi utilizado um sistema de gabarito para coleta dos sinais eletromiográficos. Acredita-se que o protocolo elaborado possa ter contribuído para a alta reprodutibilidade dos parâmetros analisados.

Os achados do presente estudo estão de acordo com estudos previamente publicados, mostrando que parâmetros da frequência apresentam uma alta reprodutibilidade e baixos valores de EPM (33,38,89). Ferrari, et al., (2014) avaliou a reprodutibilidade das bandas de frequência durante a subida de escadas em indivíduos com e sem DFP e os resultados apresentaram valores de ICC acima de 0.73 para as bandas de baixa e média frequência. Outro estudo, analisou o sinal eletromiográfico durante a descida de escada, e os valores de ICC foram superiores à 0.72 para as bandas de baixa e média frequência com EPM em torno de $10 \%$ da média da intensidade das bandas. Portanto, percebe-se que as bandas de frequência são medidas estáveis, pois são reprodutíveis e precisos, permitindo que sejam utilizados na prática clínica.

\subsection{ANÁLISE QUALITATIVA DO SINAL ELETROMIOGRÁFICO: GRUPO CONTROLE VS GRUPO DFP}

Neste estudo foram testados dois métodos de análise do sinal eletromiográfico com o intuito de encontrar um parâmetro ideal para caracterização dos indivíduos com DFP. A Fz e a LR foram utilizadas como referência para análise do sinal eletromiográfico dos músculos VM e VL. A hipótese era de que mulheres com DFP apresentariam alterações nos parâmetros da frequência para ambas análises (Fz e LR). Esta hipótese foi atendida, as mulheres com DFP apresentaram alterações nas bandas de frequência em ambas análises. Além disso, testou-se a hipótese de que as alterações eletromiográficas teriam correlação com a dor 
reportada. Os resultados revelaram que as alterações eletromiográficas apresentaram correlação significativa com a dor reportada. Na comparação entre grupos, observou-se que: i) as bandas I e II, para ambos os músculos, mostraram-se alteradas no grupo DFP na análise do sinal eletromiográfico correspondente à Fz; ii) as bandas I, II e IV, para o músculo VL, mostraram-se alteradas no grupo DFP na análise do sinal correspondente à LR; iii) todos os parâmetros correspondentes à $\mathrm{Fz}$ que se encontraram alterados em mulheres com dor, apresentaram correlação significativa com a dor reportada, da mesma forma as bandas II e IV do sinal eletromiográfico correspondente à LR apresentaram correlação significativa.

Na comparação entre os grupos as bandas I e II mostraram-se alteradas no grupo DFP para ambas análises. Observa-se que mulheres com dor apresentam um padrão de ativação oposto ao do grupo controle para estas bandas. Enquanto o grupo controle apresenta altas intensidades na banda I, o grupo DFP apresenta baixas intensidades na mesma banda. $\mathrm{O}$ mesmo padrão de inversão é observado na banda II onde baixas intensidades são observadas no grupo controle e altas intensidades são observadas no grupo DFP. Estes resultados estão de acordo com estudos prévios que evidenciam alterações nas bandas de frequência $(33,38,62)$. Briani, et al, 2015 analisou o sinal eletromiográfico dos músculos VM e VL na descida de escada e evidenciou que mulheres com DFP apresentam alterações na banda II do VM e banda II e III do VL quando comparado ao grupo controle. Já no estudo de Ferrari, et al. 2014 os sinais eletromiográficos foram coletados na subida de escada e as bandas I/ II para o VM e a banda II do VL apresentaram-se alteradas. Resultados controversos foram observados apenas para a banda III do estudo de Briani, et al., uma vez que no presente estudo esta banda não se apresentou alterada nas mulheres com DFP. Essas diferenças podem estar associadas ao gesto em que a coleta do sinal eletromiográfico foi realizada. Porém, para as outras bandas que se mostraram alteradas em ambos os estudos, evidenciou-se o padrão invertido observado no presente estudo. 
As diferenças no espectro de frequência, mais especificamente na banda I e II do VL e VM, são unanimes nos estudos com DFP, entretanto, pouco se sabe sobre as implicações fisiológicas e clínicas destas alterações. Um caminho possível para entender tais diferenças é por meio da análise qualitativa do espectro de potência que permite a avaliação da composição muscular em relação ao tipo de fibra muscular ou dos padrões de contração muscular das UM $(51,53-57,90)$. De acordo com a literatura, fibras de contração lenta (tipo I) são representadas por bandas de baixas frequências e fibras de contração rápida (tipo II) por componentes de bandas de altas frequências (51,54-56). Logo, por meio da análise da densidade do espectro de potência é possível estimar a proporção das fibras e os padrões de atividade das UM (53,55,57). Gerdle et al. (1991)(56) investigou a possibilidade da Fm do eletromiograma dos músculos extensores de joelho ser dependente da força e/ou tipo de fibra. Os resultados do estudo evidenciaram uma correlação positiva entre a Fm e o torque extensor de joelho (VM r = 0.87; VL r = 0.76), assim, o aumento gradual do torque foi acompanhado pelo aumento da Fm. Este estudo ainda realizou biópsia do músculo VL e encontrou uma correlação negativa entre fibras tipo I e a Fm, logo, quanto maior a Fm, menor a proporção de fibras tipo I. Baseados nestes resultados, os autores concluem que a Fm é dependente da proporção do tipo de fibras, e portanto, o espectro de potência pode ser usado como um indicador do recrutamento de UM.

Outro estudo, desenvolvido por Wakeling, et al., (2004) (54), testou se as propriedades espectrais do sinal eletromiográfico poderiam estar relacionadas a diferentes UM dos músculos extensores de joelho. Para tanto, foi testado o reflexo h (estimulação elétrica) e de estiramento e a contração isométrica gradual, pois eles apresentam diferentes padrões de recrutamento das UM. De acordo com a literatura, na contração isométrica gradual UM lentas são recrutadas antes das rápidas (59), na estimulação elétrica, fibras rápidas (tipo II) são preferencialmente recrutadas e no reflexo de estiramento as fibras lentas (tipo I) são 
preferencialmente recrutadas (60,61). Os resultados de Walkeling, et al (2004) (54), mostraram que na estimulação elétrica pode ocorrer o recrutamento preferencial das UM rápidas, as quais geraram componentes de altas frequências, enquanto que no reflexo de estiramento observou-se componentes de baixas frequências. Durante a rampa de contração as UM são recrutadas na ordem de lentas para rápidas, e componentes de altas frequências do sinal mioelétrico apareceram quando UM rápidas foram recrutadas (54).

Dessa forma, baseado na literatura, pode-se assumir que altas frequências estão associadas ao recrutamento de UM rápidas o que inclui o recrutamento de fibras tipo II e baixas frequências às UM lentas (fibras tipo I) (51,54-57). Apesar de não estar definido na literatura quais são as frequências que definem uma banda de baixa ou alta frequência, sabe-se que na mudança gradual de baixas frequências para altas, existe uma transição de recrutamento de UM lentas para rápidas. Sendo assim, no presente estudo, observam-se intensidades altas na banda I ( 15 - 45Hz) e intensidades baixas na banda II $(45-96 \mathrm{~Hz})$ para o grupo controle quando comparado ao grupo DFP, logo, observa-se que no momento em que é solicitado um predomínio de recrutamento de fibras tipo I em uma condição saudável, ocorre o inverso no grupo DFP. Comportamento similar ocorre no recrutamento de fibras tipo II, enquanto no grupo controle estas fibras não são muito solicitadas, no grupo DFP elas são preferencialmente recrutadas.

De acordo com a literatura, quanto maior a força desenvolvida, maior é a presença de componentes de alta frequência e o recrutamento de UM rápidas (fibras tipo II) $(54,56,91)$. Logo, considera-se o gesto de subida de escada uma atividade que requer uma demanda baixa de força, pois observou-se o predomínio de altas intensidades espectrais na banda I (15 a 45Hz) e baixíssimas intensidades na banda III (96 a 400Hz) para ambos os grupos. Estudos evidenciam, que é possível atingir frequências de aproximadamente $378 \mathrm{~Hz}$ à $76 \%$ da CVM para o VL e $415 \mathrm{~Hz}$ à $79 \%$ da CVM para o VM, enquanto que frequências em torno de $53 \mathrm{~Hz}$ à 
12\% da CVM para o VL e 32Hz para 14\% da CVM para o VM (54). Assim, entende-se que a tarefa de subir escada não requer uma demanda elevada de força, e, portanto, UM rápidas não são preferencialmente recrutadas. Entretanto, mulheres com DFP apresentaram altas intensidades em bandas de maior frequência e, portanto, parecem recrutar mais fibras tipo II (frequentes em atividades intensas) que às mulheres do grupo controle para desenvolver a mesma tarefa. De acordo com a literatura, a fraqueza do músculo quadríceps está associada a presença de DFP (12) e é considerada um fator de risco para esta desordem $(26,92)$. Neste contexto, é possível que mulheres com DFP recrutam mais UM rápidas como estratégia de compensação, melhorando a força de contração durante a tarefa de subida de escada. Cabe destacar, ainda, que as fibras tipo II são caracterizadas por apresentarem uma maior capacidade de geração de força quando comparada às tipo I (93-95). Assim, este padrão alterado de recrutamento muscular do VM e VL das mulheres com DFP pode gerar forças de diferentes amplitudes influenciando no adequado alinhamento da patela durante atividades dinâmicas e, consequentemente desencadeando a sintomatologia da DFP pelo atrito entre a patela e o côndilo femoral.

Recentemente, um estudo (53) avaliou a atividade muscular do membro inferior de sujeitos com osteoartrite (OA) de joelho durante o movimento de levantar e sentar. Os resultados evidenciaram que sujeitos com OA não apresentam alteração da Fm para o músculo VM quando comparados ao grupo controle, entretanto, diferenças foram observadas para o músculo reto femoral (RF) (53). Cabe destacar, que a Fm é um parâmetro que representa o comportamento global do espectro de frequência, não evidenciando pequenas alterações ou especificidades do espectro de potência do VM. Neste estudo de Annan et al, (2016) uma análise mais específica do espectro de potência foi realizada apenas para o músculo RF a qual evidenciou que a proporção de bandas de baixa frequência era menor nos sujeitos com OA que no grupo controle. De maneira oposta, a proporção de bandas de alta 
frequência era maior em sujeitos com OA que sujeitos controles para o RF (53). Os autores, concluíram que para melhorar a força de contração durante a extensão do joelho os pacientes com OA utilizaram a estratégia de ativar mais fibras tipo II para compensar a fraqueza da musculatura do quadríceps. Apesar das diferenças metodológicas entre o estudo mencionado e o presente estudo, observa-se um padrão um tanto semelhante em relação ao recrutamento de fibras musculares dos pacientes com dor. Interessantemente, a literatura aponta para uma possível associação entre a DFP e a OA $(6,7)$, e os resultados do presente estudo vão ao encontro desta hipótese uma vez que ambas populações apresentam padrões de recrutamento muito semelhantes. Futuros estudos são necessários para investigar se este padrão de recrutamento pode ser a causa/consequência destas patologias e possivelmente estabelecer um link entre estas desordens.

O músculo quadríceps, em uma condição normal, atua na extensão do joelho, sendo que os músculos VM e VL apresentam, também, a função de estabilizadores articulares, especialmente da patela (96-98). Toumi, et al., (2007) mostraram que os músculos VM e VL ativam simultaneamente em atividade dinâmicas, sendo que o VM apresenta um aumento na ativação quando o joelho é desestabilizado (durante o salto), suportando a ideia de que o VM não atua apenas na extensão de joelho, mas também como estabilizador medial da patela, auxiliando na manutenção do deslocamento normal da patela no leito troclear durante atividades dinâmicas (98). Estudos desenvolvidos por Flaxman, et al., (2012 e 2017) $(96,97)$ revelaram que o VM e VL são considerados estabilizadores gerais da articulação do joelho, uma vez que estes músculos demostraram uma ativação independente da direção da carga, apresentando magnitudes de ativação similar em todas as direções da FRS. Os autores postulam que os músculos estabilizadores, VM e VL, contraem para aumentar forças compressivas na articulação do joelho, criando uma articulação mecanicamente estável e a partir disso, os músculos que demostram ativação na direção da carga (correspondente à 
orientação do braço de momento) possam iniciar e transmitir as forças dirigidas. Ou seja, os músculos VM e VL contraem para estabilizar a articulação do joelho, para posteriormente o músculo RF, por exemplo, promover a extensão de joelho. Considerando que a ativação dos músculos VM e VL está alterada em sujeitos com DFP, principalmente pela alteração no recrutamento de UM, este mecanismo de estabilização pode estar comprometido. Sabe-se que as fibras tipo I apresentam maior resistência à fadiga e, portanto, apresentam papel fundamental na manutenção da postura e estabilidade segmentar (93-95). Dessa forma, considerando que sujeitos com DFP apresentam uma diminuição no recrutamento de UM lentas e consequentemente fibras tipo I, é possível que os músculos VM e VL não promovam a estabilização adequada da articulação patelofemoral previamente à contração dos outros músculos e/ou durante a realização do movimento propriamente dito. Assim, sem a estabilização adequada a patela fica vulnerável à movimentos anormais no leito troclear durante atividades dinâmicas.

O design deste estudo não permite estabelecer as causas destes padrões eletromiográficos, entretanto baseado na literatura algumas inferências podem ser feitas. Sabe-se que o músculo quadríceps apresenta-se inibido na presença de dor, seja ela na dor crônica, induzida ou pela antecipação da dor (99-101). Dentre os possíveis mecanismos envolvidos no processo de inibição muscular, a literatura evidencia que mulheres com DFP apresentam diminuição do reflexo h do músculo VM, o qual pode estar associado ao aumento da inibição pré-sináptica do músculo quadríceps $(99,102)$. De acordo com a literatura, a amplitude da inibição pré-sináptica pode depender do tipo de unidade motora, assim, a resposta das UM de contração lenta são mais fortemente deprimidas pela inibição que aquelas UM de contração rápida (103). Cabe salientar, também, que inibições recorrentes dos motoneurônios, mediadas pelas células de Renshaw, diferem entre os tipos de UM, onde UM de contração rápida (mais fadigáveis) são menos inibidas que as UM de contração lenta 
(resistentes à fadiga), ou seja, a atividade das UM lentas é preferencialmente inibida pelas células de Renshaw (95). Portanto, observa-se que em um processo inibitório, mais especificamente na inibição pre-sináptica Ia, as fibras tipo I podem ser preferencialmente inibidas quando comparadas às fibras tipo II. Estes achados, podem auxiliar na compreensão dos resultados do presente estudo, uma vez que foi observada uma diminuição na intensidade das bandas de baixa frequência, indicando que o recrutamento das fibras tipo I pode estar reduzida em mulheres com DFP. De acordo com o estudo de Tucker, et al., (2009) (104), múltiplas mudanças na atividade dos motoneurônios são observados em estudos com dor induzida, as quais incluem uma lenta ou cessação da ativação de algumas UM e o recrutamento de outras. Este padrão não pode ser explicado por uma inibição uniforme dos motoneurônios agonistas como sugerido pela teoria de adaptação da dor e fornece um mecanismo alternativo para mudanças no controle motor durante a dor (104). Logo, o aumento da intensidade na banda II (UM rápidas - fibras tipo II), observado em pacientes com DFP pode se referir a uma estratégia compensatória frente a inibição das fibras tipo I (baixa intensidade na banda I) para que conseguissem desempenhar a tarefa de subida de escada.

Os achados deste estudo evidenciaram que mulheres com DFP apresentam alteração eletromiográfica no domínio da frequência para ambos os processamentos, os quais apresentam correlação significativa tanto com os níveis de dor quanto com a dor dicotomizada. Apesar de as bandas de frequência correspondentes à LR apresentarem correlação com a dor, os valores foram menores que os parâmetros correspondentes à Fz, variando de pequena a moderada correlação $(0.24-0.31)$. Já as bandas de frequência correspondentes à $\mathrm{Fz}$ tiveram correlação variando de pequena a grande $(0.26$ - 0.61), evidenciando que o sinal eletromiográfico correspondente à Fz parece representar melhor a condição das mulheres com DFP. O parâmetro que apresentou melhor correlação com a dor foi a banda II para o VL, onde altas intensidades desta banda estão associadas com altos 
níveis de dor, bem como a presença de dor. A comparação destes resultados com a literatura é limitada, pois não foram encontrados estudos com design metodológico semelhante. Entretanto, outros parâmetros cinemáticos e eletromiográficos foram associados com a dor e apresentaram correlação semelhante. Nakagawa, et al, (2013) encontrou que excessiva adução de quadril, rotação interna do quadril e abdução do joelho estão associados com altos níveis de dor e diminuição da função em indivíduos com DFP (15). Ainda, Briani, et al, encontrou que mulheres com DFP que realizavam atividades de alta intensidade reportaram altos níveis de dor, o qual foi associado com o atraso da ativação do VM comparado com mulheres com baixos níveis de dor e atividade física (105). Portanto, observa-se que muitos fatores estão associados com a dor em pacientes com DFP e, enquanto não se esclarece o que é causa e consequência, considera-se a DFP como uma desordem multifatorial.

Ao assumir a associação entre as bandas de frequência e os tipos de UM recrutadas e seus respectivos tipos de fibra, algumas limitações devem ser consideradas. Cabe destacar que as inferências feitas a partir da literatura, são baseadas em estudos experimentais, onde as condições de coleta diferem da apresentada neste estudo. Por exemplo, estudos que associaram as bandas de frequência com os tipos de fibra, não foram realizados durante atividade de subida de escada. Portanto, a aplicação destes resultados requer cautela, pois as estratégias de recrutamento podem variar dependendo da tarefa desenvolvida. Ainda, o espectro de potência pode ser influenciado por fatores como o "efeito volume-condutor". Assim, o sinal eletromiográfico oriundo de UM distantes do eletrodo de captação ou de UM longe da superfície de captação (profundas), pode resultar em baixas frequências e vice-versa. Entretanto, cuidados metodológicos foram tomados para que estes efeitos fossem minimizados. Previamente ao posicionamento dos eletrodos, foi identificado o ponto motor e à $2 \mathrm{~cm}$ de distância dele na direção do ventre muscular os eletrodos foram fixados, como recomendado por De Luca, 1997 (47). Este procedimento foi realizado para ambos os grupos, 
assim, se existe algum efeito relacionado ao posicionamento dos eletrodos, este efeito está presente em todas as amostras. Além disso, acreditamos que o efeito volume-condutor não atuou massivamente nos sinais eletromiográficos, uma vez que diferenças nas bandas de frequência foram identificadas. Outro fator que pode contribuir para mudanças espectrais é a distribuição heterogênea das diferentes fibras musculares, porém os músculos VM e VL apresentam uma distribuição aleatória de fibras tipo I e II em adultos jovens $(106,107)$. Baseado na literatura, a duração da dor em desordens musculoesqueléticas tem influência direta na composição muscular, uma vez que condições crônicas (dor de longa data) estão associadas com menor proporção de fibras tipo I e maior de tipo II $(108,109)$. Entretanto, esta variável, não foi monitorada no presente estudo, a qual poderia auxiliar na interpretação dos resultados. Portanto, sugere-se que estudos futuros atendam esta lacuna, investigando se pacientes com DFP crônica (dor de longa data) apresentam composição muscular diferente daqueles agudos ou saudáveis.

\subsection{CAPACIDADE DISCRIMINATÓRIA E FATOR DE RISCO}

A capacidade discriminatória é uma análise que permite investigar o quanto uma ferramenta ou variável é sensível e específica para identificar a presença ou ausência de uma desordem. Além disso, por meio desta análise é possível extrair informações reais da proporção de indivíduos com alteração EMG que não podem ser visualizadas em uma simples comparação entre grupos. Valores ideais de capacidade discriminatória incluem área sob a curva (AUC) de 1.0 e valores próximos de $100 \%$ de especificidade e sensibilidade. Os resultados do presente estudo não atingem estes valores, entretanto, são os melhores observados até o momento para parâmetros biomecânicos em geral. Dentre os parâmetros analisados, destaca-se a banda II do VM e VL, pois apresentaram AUC de 0.78 (sensibilidade 
- 0.71 e especificidade -0.70 ) e 0.87 (sensibilidade -0.82 e especificidade -0.80 ) respectivamente.

Ferrari et al, 2014 investigou a acurácia diagnóstica de parâmetros EMG em mulheres com DFP durante a subida de escada. Neste estudo, a banda II associada à dor referida foi considerada como referência padrão a qual apresentou $70 \%$ de sensibilidade e $87 \%$ de especificidade. Diferenças metodológicas como o método de classificação das mulheres com DFP (intervalo de confiança de 95\%), tamanho da amostra e a própria referência padrão (Banda II associada a dor reportada), podem justificar os diferentes resultados entre o presente estudo e o de Ferrari, et al. (2014). Cabe salientar, que se tratando de uma ferramenta que visa discriminar mulheres com DFP é importante que valores de sensibilidade sejam superiores, respeitando a recomendação da literatura de que a sensibilidade e especificidade devem ser equilibradas. Os resultados do presente estudo atendem tal assertiva.

Parâmetros do domínio da frequência do sinal eletromiográfico também foram testados na descida de escada (33), entretanto os resultados de capacidade discriminatória foram inferiores ao do presente estudo. A banda II para os músculos VM e VL apresentaram ASC de 0.71 (sensibilidade -0.72 e especificidade -0.69 ) e 0.71 (sensibilidade -0.68 e especificidade - 0.62), respectivamente. Outros parâmetros, como a amplitude de movimento da eversão do retropé (Sensibilidade - 0.72 e especificidade - 0.63) (23), pico de eversão do retropé (Sensibilidade - 0.58 e especificidade - 0.67), pico de adução do quadril (Sensibilidade - 0.67 e especificidade - 0.77), pico de flexão de joelho (Sensibilidade -0.63 e especificidade - 0.45) (110) e reflexo h (Sensibilidade - 0.73 e especificidade - 0.67) (99) apresentaram capacidade discriminatória inferior à o presente estudo para a banda II do músculo VL. Portanto, percebe-se que alterações eletromiográficas dos músculos estabilizadores da patela estão presentes nas mulheres com DFP, sendo que aproximadamente 80\% das mulheres do grupo DFP apresentam alteração na banda II do VL. Dessa forma, as 
alterações eletromiográficas devem ser consideradas tanto para o diagnóstico da DFP como nas propostas de tratamento. Portanto, estudos futuros que visam formar subgrupos de pacientes com DFP baseado em alterações biomecânicas, devem considerar as alterações eletromiográficas do VM e VL.

Como apresentado anteriormente, mulheres com DFP apresentam alterações eletromiográficas nos músculos estabilizadores da patela, sendo que altas intensidades na banda II do VL apresentaram melhor capacidade discriminatória e grande correlação com a dor. Após três anos da identificação desta alteração eletromiográfica, observou-se que $45 \%$ do grupo controle apresenta dor e $25 \%$ do grupo com DFP não tem dor. Considerando que o cálculo da capacidade discriminatória contabilizou $20 \%$ de falsos negativos e $18 \%$ de falsos positivos, percebe-se que as alterações EMG não explicam totalmente a presença da dor. Entretanto, observou-se que $80 \%$ das voluntárias que apresentavam altas intensidades na banda II do VL reportaram dor após três anos, evidenciando que mulheres com alterações eletromiográficas tem 4.5 vezes mais chance de ter dor do futuro que aquelas sem alteração no VL. Cabe destacar, ainda, que a associação entre altas intensidades na banda II do VL e a presença de dor no dia da avaliação, apresentou OR de $6.15(\mathrm{p}=0.0002)$, fortalecendo a ideia de que a alteração eletromiográfica do VL pode ser considerada um fator de risco para DFP. Estes achados sugerem que as alterações eletromiográficas devem ser consideradas no contexto clínico tanto para prevenção quanto para tratamento da DFP.

A literatura não apresenta estudos que abordaram as alterações eletromiográficas no domínio da frequência em ambiente clínico. Portanto, não existem relatos de que estas alterações eletromiográficas são fatores de risco modificais. Além disso, estudos prospectivos não foram realizados para entender se as alterações eletromiográficas correspondem à causa ou consequência da dor e, portanto, é difícil estabelecer uma conduta terapêutica para prevenir ou tratar esta alteração. Entretanto, possíveis intervenções podem ser propostas ao considerar 
os resultados do presente estudo. Basicamente, dois mecanismos foram destacados como possíveis fatores associados à DFP. Primeiramente, destacou-se a alteração do recrutamento de UM, com diminuição no recrutamento de UM lentas (fibras tipo I - posturais) e aumento do recrutamento de UM rápidas (fibras tipo II), podendo alterar o mecanismo de estabilização da patela durante atividades dinâmicas. Sabe-se que treinamentos específicos, como de endurance/resistência promovem a ativação de fibras tipo I e podem causar a conversão de fibras de contração rápida (fibras tipo II) em fibras de contração lenta (tipo I)(111). Neste contexto, estudos clínicos devem testar a efetividade da inclusão de exercícios de resistência em protocolos de tratamento para pacientes com DFP. Secundariamente, destacou-se que as alterações de recrutamento podem ser decorrentes de um processo inibitório. Neste contexto, uma possível estratégia é implementar nos protocolos de tratamento técnicas que visam intervir no processo inibitório, como a eletroterapia, crioterapia, dentre outras $(112,113)$. 


\section{CONCLUSÃO}

Os resultados do presente estudo evidenciaram que parâmetros do domínio da frequência correspondentes à Fz e à LR são reprodutíveis e precisos para ambos os músculos e grupos. Em ambos os processamentos, alterações eletromiográficas foram encontradas em mulheres com DFP. Entretanto, os parâmetros correspondentes à Fz apresentaram valores de superiores de correlação com a dor e de capacidade discriminatória que o segundo processamento. De maneira geral, as mulheres com DFP apresentam um padrão invertido de ativação quando comparado a mulheres saudáveis. Enquanto no grupo controle altas intensidades são observadas na banda de baixa frequência e baixas intensidades na banda de maior frequência, o grupo com dor apresenta o contrário.

De maneira mais específica, a banda II do músculo VL apresentou forte correlação positiva com a dor, além de discriminar com aproximadamente $90 \%$ de precisão mulheres com e sem dor. Além disso, a exposição à esta alteração eletromiográfica está associada com a presença de dor tanto na análise retrospectiva quanto prospectiva, caracterizando-se como um possível fator de risco para DFP.

Neste contexto, os resultados do presente estudo, permitem concluir que mulheres com DFP apresentam alterações eletromiográficas nos músculos estabilizadores da patela, evidenciando que alterações de controle neuromuscular devem ser consideradas na estratégias de avaliação, tratamento e prevenção da DFP. 


\section{REFERÊNCIAS BIBLIOGRÁFICAS}

1. Wood L, Muller S, Peat G. The epidemiology of patellofemoral disorders in adulthood: a review of routine general practice morbidity recording. Prim Health Care Res Dev [Internet]. 2011 Apr;12(2):157-64.

2. Morelli V, Braxton TM. Meniscal, plica, patellar, and patellofemoral injuries of the knee: updates, controversies and advancements. Prim Care. Elsevier Inc; 2013 Jun;40(2):357-82.

3. Crossley KM, van Middelkoop M, Callaghan MJ, Collins NJ, Rathleff MS, Barton CJ. 2016 Patellofemoral pain consensus statement from the 4th International Patellofemoral Pain Research Retreat, Manchester. Part 2: recommended physical interventions (exercise, taping, bracing, foot orthoses and combined interventions). Br J Sports Med [Internet]. 2016;0:1-9.

4. Hiemstra LA, Kerslake S, Irving C. Anterior knee pain in the athlete. Clin Sports Med [Internet]. $2014 \mathrm{Jul}$ [cited 2014 Aug 29];33(3):437-59.

5. Stathopulu E. Anterior knee pain: a long-term follow-up. Rheumatology [Internet]. 2003 Feb;42(2):380-2.

6. Utting MR, Davies G, Newman JH. Is anterior knee pain a predisposing factor to patellofemoral osteoarthritis? Knee. 2005 Oct;12(5):362-5.

7. Wyndow N, Collins N, Vicenzino B, Tucker K, Crossley K. Is There a Biomechanical Link Between Patellofemoral Pain and Osteoarthritis? A Narrative Review. Sports Med [Internet]. Springer International Publishing; 2016;46(12):1797-808.

8. Boling M, Padua D, Marshall S, Guskiewicz K, Pyne S, Beutler A. Gender differences in the incidence and prevalence of patellofemoral pain syndrome. Scand J Med Sci Sports. 2011;20(5):725-30.

9. Earl JE, Vetter CS. Patellofemoral Pain. Phys Med Rehabil Clin N Am. 2007;18(3):439-58.

10. Powers CM, Bolgla L a, Callaghan MJ, Collins N, Sheehan FT. Patellofemoral pain: proximal, distal, and local factors, 2nd International Research Retreat. J Orthop Sports Phys Ther [Internet]. 2012 Jun;42(6):A1-54.

11. Nakagawa TH, Moriya ÉTU, Maciel CD, Serrão FV. Trunk, Pelvis, Hip, and Knee Kinematics, Hip Strength, and Gluteal Muscle Activation During a Single Leg Squat in Males and Females With and Without Patellofemoral Pain Syndrome. J Orthop Sports Phys Ther. 2012;42(6):491-501.

12. Lankhorst NE, Bierma-Zeinstra SM a, van Middelkoop M. Factors associated with patellofemoral pain syndrome: a systematic review. Br J Sports Med [Internet]. 2012 Mar;47(4):193-206.

13. Souza RB, Powers CM. Differences in Hip Kinematics, Muscle Strength, and Muscle Activation Between Subjects With and Without Patellofemoral Pain. J Orthop Sport Phys Ther [Internet]. 2009;39(1):12-9.

14. Meira EP, Brumitt J. Influence of the hip on patients with patellofemoral pain syndrome: a systematic review. Sports Health. 2011 Sep;3(5):455-65.

15. Nakagawa TH, Serrão F V, Maciel CD, Powers CM. Hip and Knee Kinematics are Associated with Pain and Self-reported Functional Status in Males and Females with 
Patellofemoral Pain. Int J Sports Med [Internet]. 2013 Jun 14;34(11):997-1002.

16. Noehren B, Pohl MB, Sanchez Z, Cunningham T, Lattermann C. Proximal and distal kinematics in female runners with patellofemoral pain. Clin Biomech (Bristol, Avon) [Internet]. Elsevier Ltd; 2012 May;27(4):366-71.

17. Song CY, Huang HY, Chen SC, Lin JJ, Chang AH. Effects of femoral rotational taping on pain, lower extremity kinematics, and muscle activation in female patients with patellofemoral pain. J Sci Med Sport [Internet]. Sports Medicine Australia; 2015;18(4):388-93.

18. Huberti HH, Hayes WC. Patellofemoral contact pressures: The influence of Q-angle and tendofemoral contact. J bone Jt surgery Am. 1984;66(5):715-24.

19. Noehren B, Hamill J, Davis I. Prospective evidence for a hip etiology in patellofemoral pain. Med Sci Sports Exerc. 2013 Jun;45(6):1120-4.

20. McKenzie K, Galea V, Wessel J, Pierrynowski M. Lower extremity kinematics of females with patellofemoral pain syndrome while stair stepping. J Orthop Sports Phys Ther. 2010 Oct;40(10):625-32.

21. Barton CJ, Menz HB, Levinger P, Webster KE, Crossley KM. Greater peak rearfoot eversion predicts foot orthoses efficacy in individuals with patellofemoral pain syndrome. Br J Sports Med. 2011 Jul;45(9):697-701.

22. Lack S, Barton C, Malliaras P, Twycross-Lewis R, Woledge R, Morrissey D. The effect of anti-pronation foot orthoses on hip and knee kinematics and muscle activity during a functional step-up task in healthy individuals: a laboratory study. Clin Biomech (Bristol, Avon). Elsevier B.V.; 2014 Feb;29(2):177-82.

23. De Oliveira Silva D, Briani RV, Pazzinatto MF, Ferrari D, Aragão FA, Albuquerque $\mathrm{CE}$, et al. Reliability and differentiation capability of dynamic and static kinematic measurements of rearfoot eversion in patellofemoral pain. Clin Biomech (Bristol, Avon) [Internet]. Elsevier Ltd; 2015 Dec;30(2):144-8.

24. Tiberio D. The effect of excessive subtalar joint pronation on patellofemoral mechanics: a theoretical model. J Orthop Sports Phys Ther. 1987;9(4):160-5.

25. Barton CJ, Levinger P, Menz HB, Webster KE. Kinematic gait characteristics associated with patellofemoral pain syndrome: a systematic review. Gait Posture. Elsevier Ltd; 2009 Nov;30(4):405-16.

26. Boling MC, Padua D a, Marshall SW, Guskiewicz K, Pyne S, Beutler A. A prospective investigation of biomechanical risk factors for patellofemoral pain syndrome: the Joint Undertaking to Monitor and Prevent ACL Injury (JUMP-ACL) cohort. Am J Sports Med [Internet]. 2009 Nov;37(11):2108-16.

27. Petersen W, Ellermann A, Gosele-Koppenburg A, Best R, Rembitzki IV, Bruggemann G-P, et al. Patellofemoral pain syndrome. Knee Surg Sport Traumatol Arthrosc. 2014;22(10):2264-74.

28. Pal S, Draper CE, Fredericson M, Gold GE, Delp SL, Beaupre GS, et al. Patellar maltracking correlates with vastus medialis activation delay in patellofemoral pain patients. Am J Sports Med. 2011;39:590-8.

29. Cavazzuti L, Merlo A, Orlandi F, Campanini I. Delayed onset of electromyographic activity of vastus medialis obliquus relative to vastus lateralis in subjects with patellofemoral pain syndrome. Gait Posture [Internet]. Elsevier B.V.; 2010;32(3):2905. 
30. Aminaka N, Pietrosimone BG, Armstrong CW, Meszaros A, Gribble PA.

Patellofemoral pain syndrome alters neuromuscular control and kinetics during stair ambulation. J Electromyogr Kinesiol [Internet]. Elsevier Ltd; 2011;21(4):645-51.

31. Rathleff MS, Samani A, Olesen JL, Roos EM, Rasmussen S, Christensen BH, et al. Neuromuscular activity and knee kinematics in adolescents with patellofemoral pain. Med Sci Sports Exerc. 2013;45(Vm):1730-9.

32. Bolgla L a, Malone TR, Umberger BR, Uhl TL. Comparison of hip and knee strength and neuromuscular activity in subjects with and without patellofemoral pain syndrome. Int J Sports Phys Ther [Internet]. 2011;6(4):285-96.

33. Briani RVa, Silva DO, Ferraz M, Albuquerque CE, Ferrari D, Aragão FA, et al. Comparison of frequency and time domain electromyography parameters in women with patellofemoral pain. Clin Biomech [Internet]. Elsevier Ltd; 2015;30(3):302-7.

34. Wong Y. Recording the vastii muscle onset timing as a diagnostic parameter for patellofemoral pain syndrome: fact or fad? Phys Ther Sport [Internet]. Elsevier Ltd; 2009 May;10(2):71-4.

35. Chester R, Smith TO, Sweeting D, Dixon J, Wood S, Song F. The relative timing of VMO and VL in the aetiology of anterior knee pain: a systematic review and metaanalysis. BMC Musculoskelet Disord [Internet]. 2008 Jan;9:64.

36. Cowan SM, Bennell KL, Hodges PW, Crossley KM, McConnell J. Delayed onset of electromyographic activity of vastus medialis obliquus relative to vastus lateralis in subjects with patellofemoral pain syndrome. Arch Phys Med Rehabil. 2001 Feb;82(2):183-9.

37. Cowan SM, Hodges PW, Bennell KL, Crossley KM. Altered vastii recruitment when people with patellofemoral pain syndrome complete a postural task. Arch Phys Med Rehabil. 2002;83:989-95.

38. Ferrari D, Kuriki HU, Silva CR, Alves N, Mícolis de Azevedo F. Diagnostic Accuracy of the Electromyography Parameters Associated With Anterior Knee Pain in the Diagnosis of Patellofemoral Pain Syndrome. Arch Phys Med Rehabil [Internet]. 2014 Aug;95(8):1521-6.

39. von Tscharner V, Valderrabano V. Classification of multi muscle activation patterns of osteoarthritis patients during level walking. J Electromyogr Kinesiol [Internet]. Elsevier Ltd; 2010 Aug;20(4):676-83.

40. Nakagawa TH, Moriya ÉTU, Maciel CD, Serrão AFV. Frontal plane biomechanics in males and females with and without patellofemoral pain. Med Sci Sports Exerc. 2012 Oct;44(9):1747-55.

41. van Eijden TM, Kouwenhoven E, Verburg J, Weijs W a. A mathematical model of the patellofemoral joint. J Biomech. 1986 Jan;19(3):219-29.

42. Crossley KM, Cowan SM, Bennell KL, McConnell J. Knee flexion during stair ambulation is altered in individuals with patellofemoral pain. J Orthop Res. 2004 Mar;22(2):267-74.

43. Milner CE, Hamill J, Davis I. Are knee mechanics during early stance related to tibial stress fracture in runners? Clin Biomech (Bristol, Avon). 2007 Jul;22(6):697-703.

44. Radin EL, Yang KH, Riegger C, Kish VL, O’Connor JJ. Relationship between lower limb dynamics and knee joint pain. J Orthop Res. 1991;9(3):398-405.

45. Mundermann A, Dyrby CO, Andriacchi T. Secondary gait changes in patients with 
medial compartment knee osteoarthritis: increased load at the ankle, knee, and hip during walking. Arthritis Rheum. 2005;52:2835-44.

46. De Oliveira Silva D, Briani RV, Pazzinatto MF, Ferrari D, Aragão FA, De Azevedo FM. Reduced knee flexion is a possible cause of increased loading rates in individuals with patellofemoral pain. Clin Biomech [Internet]. Elsevier Ltd; 2015;30(9):971-5.

47. De Luca CJ. The use of surface electromyography in biomechanics. J Appl Biomech. 1997;13(2):135-63.

48. Rocha C, Silva DDO, Briani RV, Pazzinatto F, Ferrari D, Azevedo FM De. Test-Retest Reliability of Electromyographic Signal Parameters Used To Evaluate Neuromuscular Fatigue in Quadriceps Femoris Muscle. Kinesiology. 2016;48(2):174-81.

49. Pugdahl K, Johnsen B, Tankisi H, Camdessanché JP, de Carvalho M, Fawcett PRW, et al. Added value of electromyography in the diagnosis of myopathy: A consensus exercise. Clin Neurophysiol [Internet]. International Federation of Clinical Neurophysiology; 2017;xx(xx):xx.

50. Solomonow M, Baten C, Smit JOS, Baratta R, Hermens H, Ambrosia RD. Electromyogram power spectra frequencies associated with motor unit recruitment strategies. J Appl Physiol. 1990;68(3):1177-85.

51. Wakeling JM, Pascual SA, Nigg BM, von Tscharner V. Surface EMG shows distinct populations of muscle activity when measured during sustained sub-maximal exercise. Eur J Appl Physiol. 2001;86(1):40-7.

52. Allison GT, Fujiwara T. The relationship between EMG median frequency and low frequency band amplitude changes at different levels of muscle capacity. Clin Biomech (Bristol, Avon) [Internet]. 2002 Jul;17(6):464-9.

53. Anan M, Shinkoda K, Suzuki K, Yagi M, Kito N. Dynamic Frequency Analyses of Lower Extremity Muscles during Sit-To-Stand Motion for the Patients with Knee Osteoarthritis. PLoS One [Internet]. 2016;11(1):e0147496.

54. Wakeling JM, Rozitis AI. Spectral properties of myoelectric signals from different motor units in the leg extensor muscles. J Exp Biol. 2004;207:2519-28.

55. Wakeling JM, Kaya M, Temple GK, Johnston IA, Herzog W. Determining patterns of motor recruitment during locomotion. J Exp Biol [Internet]. 2002;205(Pt 3):359-69.

56. Gerdle B, Henriksson-Larsen K, Lorentzon R, Wretling ML, Henriksson-Larsén K, Lorentzon R, et al. Dependence of the mean power frequency of the electromyogram on muscle force and fibre type. Acta Physiol Scand. 1991;142(1982):457-65.

57. Kupa EJ, Roy SH, Kandarian SC, De Luca CJ. Effects of muscle fiber type and size on EMG median frequency and conduction velocity. J Appl Physiol [Internet]. 1995;79(1):23-32.

58. Linnamo V, Strojnik V, Komi P V. EMG power spectrum and features of the superimposed M-wave during voluntary eccentric and concentric actions at different activation levels. Eur J Appl Physiol. 2002;86(6):534-40.

59. Henneman E, Somjen G, Carpenter DO. Functional significance of cell size in soinal motoneurons. J Neurol. 1965;28(3):560-80.

60. Kanda K, Burke RE, Walmsley B. Differential control of fast and slow twitch motor units in the decerebrate cat. Exp Brain Res [Internet]. 1977;29(1):57-74.

61. Stephens JA, Garnett R, Buller NP. Reversal of recruitment order of single motor units 
produced by cutaneous stimulation during voluntary muscle contraction in man. Nature. 1978. 272:362-4.

62. Ferrari D, Kuriki HU, Alves N, De Azevedo FM. Characterization of the Patellofemoral Pain Syndrome By Frequency Parameters of Emg Signal. J Biomech [Internet]. Elsevier Ltd; 2012 Jul;45(Suppl 1):S390.

63. Mikesky a E, Meyer a, Thompson KL. Relationship between quadriceps strength and rate of loading during gait in women. J Orthop Res. 2000;18(2):171-5.

64. Liikavainio T, Isolehto J, Helminen HJ, Perttunen J, Lepola V, Kiviranta I, et al. Loading and gait symmetry during level and stair walking in asymptomatic subjects with knee osteoarthritis: Importance of quadriceps femoris in reducing impact force during heel strike? Knee. 2007;14(3):231-8.

65. Milner CE, Ferber R, Pollard CD, Hamill J, Davis IS. Biomechanical factors associated with tibial stress fracture in female runners. Med Sci Sports Exerc. 2006 Feb;38(2):323-8.

66. Davis IS, Bowser BJ, Hamill J. Verical impact loading in runners with a history of patellofermoral pain syndrome. Med Sci Sports Exerc. 2010;42(Suppl. 15):682-8.

67. Pohl MB, Hamill J, Davis IS. biomechanical and anatomic factors associated with a history of plantar fasciitis in female runners. Clin J Sport Med. 2009;19:372-6.

68. Witvrouw E, Callaghan MJ, Stefanik JJ, Noehren B, Bazett-Jones DM, Willson JD, et al. Patellofemoral pain: consensus statement from the 3rd International Patellofemoral Pain Research Retreat held in Vancouver, September 2013. Br J Sports Med [Internet]. 2014 Mar;48(6):411-4.

69. Cook C, Hegedus E, Hawkins R, Scovell F, Wyland D. Diagnostic accuracy and association to disability of clinical test findings associated with patellofemoral pain syndrome. Physiother Canada. 2010;62(1):17-24.

70. Nijs J, Van Geel C, Van der auwera C, Van de Velde B. Diagnostic value of five clinical tests in patellofemoral pain syndrome. Man Ther [Internet]. 2006 Feb;11(1):69-77.

71. Cook C, Mabry L, Reiman MP, Hegedus EJ. Best tests/clinical findings for screening and diagnosis of patellofemoral pain syndrome: a systematic review. Physiotherapy [Internet]. The Chartered Society of Physiotherapy; 2012 Jun;98(2):93-100.

72. Smith TO, Davies L, Toms AP, Hing CB, Donell ST. The reliability and validity of radiological assessment for patellar instability. A systematic review and meta-analysis. Skeletal Radiol. 2011;40(4):399-414.

73. Fritz JM, Wainner RS. Examining diagnostic tests: an evidence-based perspective. Phys Ther [Internet]. 2001 Sep;81(9):1546-64.

74. Portney LG, Watkins MP. Foundations of clinical research: applications to practice. $3^{\circ}$. New Jersey: Pearson Prentice Hall; 2009.

75. Van Tiggelen D, Cowan S, Coorevits P, Duvigneaud N, Witvrouw E. Delayed vastus medialis obliquus to vastus lateralis onset timing contributes to the development of patellofemoral pain in previously healthy men: a prospective study. Am J Sports Med. 2009 Jun;37(6):1099-105.

76. Crossley KM, Bennell KL, Cowan SM, Green S. Analysis of outcome measures for persons with patellofemoral pain: Which are reliable and valid? Arch Phys Med Rehabil. 2004;85(5):815-22. 
77. Smoliga JM, Myers JB, Redfern MS, Lephart SM. Reliability and precision of EMG in leg, torso, and arm muscles during running. J Electromyogr Kinesiol [Internet]. Elsevier Ltd; 2010 Feb;20(1):e1-9.

78. Weir JP. The intraclass correlation coefficient and the SEM. J Strength Cond Res. 2005;19(1):231-40.

79. Kellis E, Katis A. Reliability of EMG power-spectrum and amplitude of the semitendinosus and biceps femoris muscles during ramp isometric contractions. J Electromyogr Kinesiol [Internet]. 2008 Jun;18(3):351-8.

80. Mathur S, Eng JJ, MacIntyre DL. Reliability of surface EMG during sustained contractions of the quadriceps. J Electromyogr Kinesiol [Internet]. 2005 Feb;15(1):102-10.

81. Denegar CR, Ball DW. Assessing Reliability and Precision of Measurement : An Introduction to lntraclass Correlation and Standard Error of Measurement. J Sport Rehabil. 1993;2:35-42.

82. Hopkins WG, Marshall SW, Batterham AM, Hanin J. Progressive statistics for studies in sports medicine and exercise science. Med Sci Sports Exerc. 2009;41(1):3-12.

83. Akobeng AK. Understanding diagnostic tests 3: Receiver operating characteristic curves. Acta Paediatr. 2007;96(5):644-7.

84. Ageberg E, Bennell KL, Hunt MA, Simic M, Roos EM, Creaby MW. Validity and inter-rater reliability of medio-lateral knee motion observed during a single-limb mini squat. BMC Musculoskelet Disord [Internet]. BioMed Central Ltd; 2010;11(1):265.

85. Barton B, Peat J. Medical Statistics: a gruide to SPSS, data analysis and critical appraisal. Second Edi. BMJ Books; 2014.

86. Lewallen S, Courtright P. Epidemiology in practice: Case-control studies. Community Eye Heal J. 1998;11(28):57-8.

87. Cardozo AC, Gonçalves M. Artigo Original Reprodutibilidade e variabilidade de parâmetros de amplitude e frequiência do sinal eletromiográfico dos músculos longuíssimo do tórax e multífido lombar durante contrações isométricas voluntárias máximas. Mot Rev Educ Física. 2008;14(4):429-39.

88. Farina D, Merletti R, Enoka RM. The extraction of neural strategies from the surface EMG. J Appl Physiol [Internet]. 2004 Apr;96(4):1486-95.

89. Pazzinatto MF, Silva D de O, Briani RV, Ferrari D, Aragão FA, Albuquerque CE de, et al. Reliability of electromyography parameters during stair deambulation in patellofemoral pain syndrome. Mot Rev Educ Física [Internet]. 2015;207-13.

90. von Tscharner V, Nigg BM. Point: spectral properties of the surface EMG can characterize/do not provide information about motor unit recruitment strategies and muscle fiber type. J Appl Physiol [Internet]. 2008 Nov;105(5):1671-3.

91. Karlsson S, Gerdle B. Mean frequency and signal amplitude of the surface EMG of the quadriceps muscles increase with torque-a study using the continuous wavelet transform. J Electromyogr Kinesiol. 2001;11:131-40.

92. Lankhorst NE, Bierma-Zeinstra SM a, van Middelkoop M. Risk factors for patellofemoral pain syndrome: a systematic review. J Orthop Sports Phys Ther. 2012 Feb;42(2):81-94.

93. Linssen W, Stegeman D, Joosten E, Binkhorst R, Merks M, Ter Laak H, et al. Fatigue 
in type I fiber predominance: a muscle force and surface EMG study on the relative role of type I and type II muscle fibers. Muscle and Nerve. 1991;14(9):829-37.

94. Linssen W, Stegeman D, Joosten E, Merks H, Ter Laak H, Binkhorst R, et al. Force and fatigue in human type I muscle fibres. A surface EMG study in patients with congenital myopathy and type I fibre predominance. Brain. 1991;114(5):2123-32.

95. Hodson-Tole EF, Wakeling JM. Motor unit recruitment for dynamic tasks: Current understanding and future directions. J Comp Physiol B Biochem Syst Environ Physiol. 2009;179(1):57-66.

96. Flaxman TE, Alkjaer T, Simonsen EB, Krogsgaard MR, Benoit DL. Predicting the Functional Roles of Knee Joint Muscles from Internal Joint Moments. Med Sci Sports Exerc. 2017;49(3):527-37.

97. Flaxman TE, Speirs AD, Benoit DL. Joint stabilisers or moment actuators: The role of knee joint muscles while weight-bearing. J Biomech [Internet]. Elsevier; 2012;45(15):2570-6.

98. Toumi H, Poumarat G, Benjamin M, Best T, F’Guyer S, Fairclough J. New insights into the function of the vastus medialis with clinical implications. Med Sci Sports Exerc. 2007;39(7):1153-9.

99. de Oliveira Silva D, Magalhães FH, Faria NC, Pazzinatto MF, Ferrari D, Pappas E, et al. Lower Amplitude of the Hoffmann Reflex in Women With Patellofemoral Pain: Thinking Beyond Proximal, Local, and Distal Factors. Arch Phys Med Rehabil [Internet]. 2016;97:1115-20.

100. Tucker K, Larsson AK, Oknelid S, Hodges P. Similar alteration of motor unit recruitment strategies during the anticipation and experience of pain. Pain [Internet]. International Association for the Study of Pain; 2012;153(3):636-43.

101. Park J, Hopkins JT. Induced anterior knee pain immediately reduces involuntary and voluntary quadriceps activation. Clin J Sport Med [Internet]. 2013 Jan;23(1):19-24.

102. de Oliveira Silva D, Magalhães FH, Faria NC, Ferrari D, Pazzinatto MF, Pappas E, et al. Vastus medialis H-reflex excitability is associated with pain level, self-reported function and chronicity in women with patellofemoral pain. Arch Phys Med Rehabil [Internet]. Elsevier Ltd; 2016;98(1):114-9.

103. Aimonetti JM, Vedel JP, Schmied A, Pagni S. Distribution of presynaptic inhibition on type-identified motoneurones in the extensor carpi radialis pool in man. $\mathrm{J}$ Physiol [Internet]. 2000;522 Pt 1:125-35.

104. Tucker KJ, Hodges PW. Motoneurone recruitment is altered with pain induced in nonmuscular tissue. Pain [Internet]. International Association for the Study of Pain; 2009;141(1-2):151-5.

105. Briani RV, de Oliveira Silva D, Pazzinatto MF, Ferreira AS, Ferrari D, de Azevedo FM. Delayed onset of electromyographic activity of the vastus medialis relative to the vastus lateralis may be related to physical activity levels in females with patellofemoral pain. J Electromyogr Kinesiol [Internet]. Elsevier Ltd; 2015;26:137-42. 2

106. Johnson MA, Polgar J, Weightman D, Appleton D. Data on the distribution of fibre types in thirty-six human muscles. An autopsy study. J Neurol Sci. 1973;18(1):111-29.

107. Lexell J. Ageing and human muscle: observations from Sweden. Can J Appl Physiol. 1993;18(1):2-18.

108. Mannion AF, Käser L, Weber E, Rhyner A, Dvorak J, Müntener M. Influence of age 
and duration of symptoms on fibre type distribution and size of the back muscles in chronic low back pain patients. Eur Spine J [Internet]. 2000;9(4):273-81.

109. Uhlig Y, Weber B, Muntener M. Fiber composition and fiber transformations in neck muscles of patients with dysfunction of the cervical spine. J Orthop Res. 1995;13(2):240-9.

110. De Oliveira Silva D, Barton CJ, Pazzinatto MF, Briani RV, De Azevedo FM. Proximal mechanics during stair ascent are more discriminate of females with patellofemoral pain than distal mechanics. Clin Biomech [Internet]. Elsevier Ltd; 2016;35:56-61.

111. Abernethy P, Thayer R, Taylor A. Acute and chronic responses of skeletal muscle to endurance and sprint excercise. Sport Med. 1990;10(6):365-89.

112. Hopkins JT, Ingersoll CD, Edwards J, Klootwyk TE. Cryotherapy and transcutaneous electric neuromuscular stimulation decrease arthrogenic muscle inhibition of the vastus medialis after knee joint effusion. J Athl Train. 2002;37(1):25-31.

113. Rice DA, McNair PJ. Quadriceps arthrogenic muscle inhibition: neural mechanisms and treatment perspectives. Semin Arthritis Rheum [Internet]. Elsevier Inc.; 2010 Dec;40(3):250-66. 


\section{APÊNDICE A - ATIVIDADES DESENVOLVIDAS}

Neste item o leitor será contextualizado, sobre as atividades desenvolvidas por mim no período em que estava cursando o doutorado, que compreende de 06/2013 a 06/2017.

Ingressei no Programa de Pós-graduação Interunidades Bioengenharia em junho de 2013. Desde então, realizei diversas atividades que contribuíram para minha formação e meu enriquecimento acadêmico. Destaco a seguir algumas destas atividades.

Primeiramente, destaco o fato de participar de um grupo de pesquisa, o qual contribuiu fortemente para meu crescimento acadêmico. A rotina de trabalho, elaboração e execução de projetos, o trabalho em equipe e a produção de artigos foram algumas das experiências que tive neste período, as quais guiarão minha conduta quando docente e/ou pesquisadora. Ainda, neste laboratório tive a oportunidade de trabalhar com diversas ferramentas da área da biomecânica como eletromiografia de superfície, cinemática e cinética. Parâmetros biomecânicos extraídos dos diferentes equipamentos foram explorados pelo nosso grupo, porém a eletromiografia de superfície foi a ferramenta que tive mais contato, sendo a peça central do meu projeto de doutorado.

Durante este período de doutorado, desenvolvi meu projeto, o qual foi desafiador e bastante enriquecedor. Além da exigência intelectual, a coleta de dados, também, exigiu dedicação. Foram avaliadas centenas de voluntárias e, apenas, 80 delas atenderam os critérios de inclusão. Cabe salientar que cada voluntária subiu a escada 10 vezes em dois dias, contabilizando uma grande quantidade de dados a serem processados. Paralelamente a execução do projeto, cumpri os 24 créditos exigidos pelo programa de pós-graduação. Os créditos foram atingidos pelo cumprimento de disciplinas oferecidas pela USP e UNESP, publicação de artigos e resumos de congresso.

Outra atividade de grande valia, foi o estágio docente que realizei e a participação na orientação de uma aluna de iniciação científica. A experiência de ministrar aula no curso de 
Fisioterapia da UNESP de Presidente Prudente, foi uma experiência valiosa, pois percebi que além da pesquisa a docência também me cativa. Além de sentir na pele a importante função que o docente tem na formação de profissionais. Também, acompanhar diretamente um aluno de iniciação científica, me expos à realidade da orientação, a qual exige, dentre outras habilidades, ponderação, paciência e compreensão. Ser docente exige bastante empenho e dedicação, mas é gratificante e motivador observar a evolução dos alunos durante um semestre e, quando o aluno que você acompanha é contemplado na primeira tentativa com uma bolsa FAPESP.

Felizmente, fui contemplada com uma bolsa CAPES para realizar o doutorado sanduíche na Universidade de Sydney. Viver em outro país foi uma experiência incrível, considerando que a Austrália é um país de primeiro mundo e é referência em pesquisa clínica na área em que estudo. Participei de seminários, simpósios, eventos científicos, treinamentos diversos (Endnote, Revman, RedCap, softwares de análise de imagens, etc), vivenciei a rotina de laboratório do grupo de pesquisa de lesões musculoesqueléticas, ajustei e finalizei meu projeto de pesquisa, coletei dados, participei de outros projetos, e escrevi uma revisão sistemática. Além de aprimorar minhas habilidades comunicativas relacionadas ao inglês. Portanto, considero que este período foi crucial para minha formação, pois foi de grande aprendizado tanto no âmbito pessoal quanto acadêmico.

Como mencionado anteriormente, tive a oportunidade de conhecer várias ferramentas de pesquisa no exterior e uma delas é o RedCap. O RedCap consiste em uma plataforma online que, além de facilitar a coleta de dados e ser um instrumento seguro para o armazenamento de dados, ele permite exportar os dados para planilhas do Excel ou para programas estatísticos instantaneamente. Considerando a praticidade e facilidade deste sistema, trabalhei para a implantação desse sistema para coleta de dados no laboratório que participo. 
O projeto que desenvolvi na Austrália, tinha relação direta com a minha área de pesquisa. Neste projeto, testamos um dispositivo vestível (shorts - bermuda) composto por eletrodos eletromiográficos que permitiam a monitoração da atividade elétrica do músculo quadríceps e isquitibial. Foram entrevistados aproximadamente 80 voluntários e apenas 39 atenderam os critérios de inclusão. O shorts foi testado quanto a sua reprodutibilidade e capacidade de discriminar indivíduos com e sem DFP. Os dados foram analisados e o artigo está em fase de finalização. Este projeto foi registrado no Australian New Zealand Clinical Trials Registry (ACTRN12615001030561), onde maiores detalhes podem ser visualizados. Um resumo deste trabalho foi elaborado e submetido ao XXVI Congress of the International Society of Biomechanics Intenational, o qual foi aprovado e será apresentado pelo Prof. Evangelos Pappas. A aprovação do projeto pelo comitê de ética da Universidade de Sydney foi bastante morosa e, portanto, foi possível aprender os métodos e conduzir uma revisão sistemática com meta-análise. O fruto deste trabalho rendeu um artigo publicado na revista The Knee no início deste ano. Considerando que o meu orientador na Austrália, o Prof. Evangelos Pappas, tem vasta experiência na condução de revisões sistemáticas com metaanalise, acredito que foi uma oportunidade única desenvolver e aprender com ele. Recentemente fui convidada pelo Prof. Evangelos Pappas a participar de outra revisão sistemática. Os trabalhos estão bem adiantados, e pretendemos em breve finalizar as análises. Esta revisão está registrada no PROSPERO (2017: CRD42017060988), onde maiores detalhes podem ser encontrados.

Com o intuito de fortalecer as parcerias com o Prof. Evangelos, e promover a internacionalização entre as instituições, participei da elaboração de um projeto para financiar o intercâmbio de pesquisadores. Este projeto foi aprovado recentemente pela FAPESP viabilizando a vinda do Prof. Evangelos e a visita do meu coorientador brasileiro à Universidade de Sydney. 
Durante o período de doutorado, participei de alguns congressos na área. No ano de 2013 ocorreu na cidade de Natal, o XXIV Congress of the international society of biomechanics. Neste congresso, foram apresentados três trabalhos. Em 2014 recebi auxílio financeiro do programa de pós-graduação e pude participar do XXIV Congresso Brasileiro de Engenharia Biomédica na cidade de Uberlândia - MG, com cinco trabalhos apresentados. Em 2015, na capital de Santa Catarina, aconteceu o XVI Congresso Brasileiro de Biomecânica, onde tivemos três trabalhos apresentados. No ano seguinte, também recebi auxílio do programa de pós-graduação e, portanto, participei do XXV Congresso Brasileiro de Engenharia Biomédica com seis trabalhos publicados nos anais do referido congresso. A participação nos congressos descritos acima foi de suma importância uma vez que possibilitou a atualização sobre os temas da área, a divulgação do grupo de pesquisa que participo e dos trabalhos realizados em nosso laboratório e o enriquecimento curricular. Além disso, a apresentação oral dos trabalhos, foi importante, pois permitiu a familiarização e o aperfeiçoamento de falar em público.

Finalmente, no decorrer deste período, 17 artigos foram publicados em revistas relevantes na área da biomecânica e fisioterapia. As revistas com maior destaque são The Knee (1 artigo), Archives of Physical Medicine and Rehabilitation (3 artigos), Kinesiology (Zagreb) (2 artigos), Clinical Biomechanics (3 artigos), Journal of Electromyography and Kinesiology (1 artigo), Journal of Applied Biomechanics (1 artigo), Fisioterapia e Pesquisa (1 arigo) e Motriz: Revista de Educação Física (Online) (2 artigo). Atualmente, três artigos estão em andamento, uma revisão, o estudo do shorts (que desenvolvi na Austrália) e um terceiro que está em processo de revisão na revista Gait and Posture. Após a finalização do doutorado, será iniciada a elaboração dos artigos oriundos da tese. 


\section{ANEXO A - APROVAÇÃO DO PROJETO PELO COMITÊ DE ÉTICA EM PESQUISA DA FCT/UNESP}

\section{FACULDADE DE CIÊNCIAS E TECNOLOGIA - UNESP/ CAMPUS DE PRESIDENTE}

\section{PARECER CONSUBSTANCIADO DO CEP}

DADOS DO PROJETO DE PESQUISA

Título da Pesquisa: ESTUDO COMPARATIVO DE PARÂMETROS DA FREQUÊNCIA DO SINAL EMG OBTIDOS POR MÉTODOS DE ANÁLISE TEMPO FREQUÊNCIA E TRANSFORMADA DISCRETA DE FOURIER APLICADOS A UM MODELO DE DIAGNÓSTICO PARA A SÍNDROME DA DOR FEMOROPATELAR

Pesquisador: Fábio Mícolis de Azevedo

Área Temática:

Versão: 2

CAAE: 31880814.3 .0000 .5402

Instituição Proponente: UNIVERSIDADE ESTADUAL PAULISTA JULIO DE MESQUITA FILHO

Patrocinador Principal: Financiamento Próprio

DADOS DO PARECER

Número do Parecer: 736.434

Data da Relatoria: 01/08/2014

Situação do Parecer:

Aprovado

Necessita Apreciação da CONEP:

Não

Considerações Finais a critério do CEP:

Em reunião realizada no dia 01.08.2014, o Comitê de Ética em Pesquisa da Faculdade de Ciências e Tecnologia - Unesp - Presidente Prudente, em concordância com o parecerista, considerou o projeto APROVADO.

Obs: Lembramos que ao finalizar a pesquisa, o (a) pesquisador (a) deverá apresentar o relatório final. 


\section{ANEXO B - PROTOCOLO DE AVALIAÇÃO PARA DFP}

Identificação

Nome:

Data da avaliação Examinador:

Exame clínico

l) Presença de dor de no mínimo 2 na articulação fêmoro-patelar no último mês e de início insidioso?

$\begin{array}{cccccccccccc}0 & 1 & 2 & 3 & 4 & 5 & 6 & 7 & 8 & 9 & 10 \\ \mid & \end{array}$

( )não: 0 pontos ( ) sim: 1ponto

II) Presença de dor em pelo menos 3 condições funcionais?
( ) agachamento por tempo prolongado
( ) ajoelhar-se
( ) permanecer muito tempo sentado
( ) praticar esportes
( ) subir ou descer escadas
( ) correr
( ) contração isométrica do quadríceps
( )não: 0 pontos ( ) sim: 1ponto

III) Apresenta dor retropatelar de no mínimo 2 no agachamento bilateral à 90?

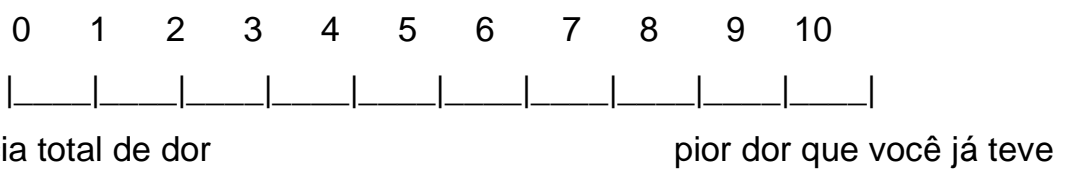

( )não: 0 pontos ( ) sim: 1ponto

IV) Apresenta dor de no mínimo 2 na descida de degrau de $25 \mathrm{~cm}$ ?

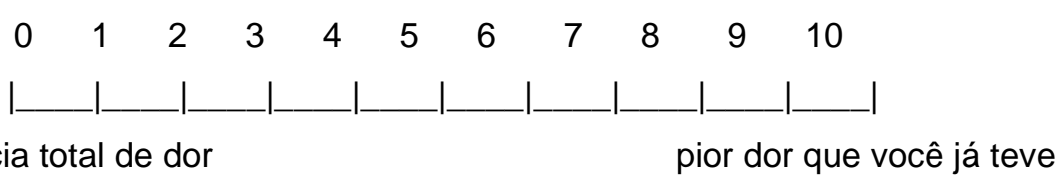

( )não: 0 pontos ( ) sim: 1ponto 
V) O indivíduo apresenta 3 sinais e sintomas clínicos positivos no mesmo membro?

\begin{tabular}{|c|c|c|}
\hline & Membro direito & Membro esquerdo \\
\hline Ângulo Q superior à $18^{\circ}$ & ( ) positivo ( ) negativo & ( ) positivo ( ) negativo \\
\hline Sinal da baioneta & ( ) positivo ( ) negativo & ( ) positivo ( ) negativo \\
\hline $\begin{array}{l}\text { Arco de movimento } \\
\text { Teste de Mconnel modificado }\end{array}$ & ( ) positivo ( ) negativo & ( ) positivo ( ) negativo \\
\hline $\begin{array}{l}\text { Dor na palpação das facetas/ } \\
\text { bordas da patela }\end{array}$ & ( ) positivo ( ) negativo & ( ) positivo ( ) negativo \\
\hline Apreensão & ( ) positivo ( ) negativo & ( ) positivo ( ) negativo \\
\hline Compressão (Clarke Test) & ( ) positivo ( ) negativo & ( ) positivo \\
\hline Crepitação (Teste de Waldron) & ( ) positivo ( ) negativo & ( ) positivo \\
\hline Torção tibial lateral & ( ) positivo ( ) negativo & ( ) positivo \\
\hline Pronação subtalar & ( ) positivo ( ) negativo & ( ) positivo ( ) negativo \\
\hline Hipermobilidade patellar & ( ) positivo ( ) negativo & ( ) positivo \\
\hline
\end{tabular}

( )não: 0 pontos ( ) sim: 1ponto

\section{Total de pontos:}

( ) $\geq 4$ : positivo para DFP

( $)<4$ : negativo para DFP 